\title{
POTENTIAL RECOGNITION OF ACCRETIONARY LAPILLI IN DISTAL IMPACT DEPOSITS ON MARS: A FACIES ANALOG PROVIDED BY THE 1.85 GA SUDBURY IMPACT DEPOSIT
}

\author{
PHILIP FRALICK \\ Department of Geology, Lakehead University, Thunder Bay, Ontario, P7B 5E1 Canada \\ e-mail: philip.fralick@lakeheadu.ca \\ AND \\ JOHN GROTZINGER AND LAUREN EDGAR \\ Division of Geological and Planetary Sciences, California Institute of Technology, Pasadena, California 91125 USA
}

\begin{abstract}
Aвstract: Our understanding of the significance and abundance of sedimentary strata on Mars has increased considerably during the last decade. The highly cratered surface of Mars leads to the prediction that impact ejecta deposits, possibly containing accretionary lapilli, should be part of the sediment record. While no impact-induced base surge deposits have been confirmed on Mars, it is likely that they will one day be discovered, and it is important to establish criteria for their recognition in the rock record. The recognition of ejecta deposits containing accretionary lapilli on Mars requires reliable facies models developed from known impact-generated strata on Earth. Sections through ejecta layers formed by the 1850 Ma Sudbury impact event provide data to begin development of such models. These deposits are laterally variable but generally show a vertical decrease in lithic clast size and, where present, an upward fining in accretionary lapilli. In thicker deposits, the accretionary lapilli-bearing portion of sections generally progresses upward from decimeter-scale beds of clast-supported lapilli interlayered with centimeter-scale sandstone beds, to parallel and undulatory laminated lapilli, and sandstones. These are overlain by lapilli stringers and isolated lapilli in parallel-laminated to cross-stratified sandstone. Both grain size and sedimentary structures indicate a succession deposited by an impact-generated base surge during decelerating flow. Thinner deposits of ejecta, possibly laid down on topographic highs, are commonly massive with reverse and normal grading. We compare the accretionary lapilli-bearing strata in the Sudbury ejecta deposits to proposed impact-generated base surge deposits in the Burns formation at Meridian Planum, Mars. Units comprising the Burns formation do not have the internal organization of spherule-bearing layers exhibited by the Sudbury ejecta deposits. Comparison with Sudbury ejecta layers and theoretical considerations indicate that the spherules developed in the Burns formation do not represent grains deposited by a base surge and are most likely diagenetic in origin. However, impact ejecta layers should be present in the sedimentary successions on Mars, and comparison with similar strata on Earth may lead to their eventual identification.
\end{abstract}

\section{INTRODUCTION}

Sedimentary rocks were first recognized on Mars only a decade ago based on observations by the Mars Global Surveyor spacecraft (Malin and Edgett 2000). Recent interpretations of data collected by the Mars Express and Mars Reconnaissance Orbiter (MRO) spacecraft have confirmed the abundance of these sedimentary rocks, and the past role of water on the Martian surface. Various depositional mechanisms, including fluvial, deltaic, lacustrine, eolian, volcaniclastic, and impact processes, have been suggested for these strata (see summary in McLennan and Grotzinger 2008). Continuing evaluation of the current stream of data being returned from active missions, supplemented by future landed missions, will further refine our understanding of each one of these different surface processes in creating a stratigraphic record.

In observing the highly cratered surface of Mars, it is logical to ask if sediment formation, transportation, and deposition processes caused by impacts may have been an important factor in the development of its sedimentary deposits. The discovery of impact megabreccia (Grant et al. 2008) in the crater walls of Holden Crater plus quantitative studies of ejecta blankets (see Barlow [2005] and references therein; Mouginis-Mark and Garbeil 2007) provide evidence that impactrelated deposits do exist on Mars. Furthermore, eroding sedimentary deposits expose ghost craters, formed at the time of deposition of these deposits (Malin and Edgett 2001), and, therefore, their associated ejecta must be part of the sedimentary record. Knauth et al. (2005) and Burt et al. (2008) stress the likely existence of impact-related deposits and specifically point to the hematite-rich spherules in the bedrock at Meridiani Planum as examples of condensation melt droplets or accretionary lapilli formed from impact-generated base surges. The formation of these spherules also has been ascribed to: precipitation from groundwater to form concretions (Squyres et al. 2004b, Grotzinger et al. 2005, McLennan et al. 2005, Squyres et al. 2006a), precipitation from hydrothermal fluids (Golden et al. 2008), reaction of sulfur-rich fluids with pyroclastic rocks (McCollom and Hynek 2005), and resedimentation of spherules formed by the interaction of volcanic deposits and acidic, hydrothermal fluids (Fan et al. 2010).

Clearly, criteria are necessary for evaluating the genesis of specific deposits in order to determine if occurrences of spherules similar to those found at Meridiani were formed by impact-related processes, or if they are of another origin. Regardless of their origin at Meridiani, which seems very likely to have been diagenetic, it is probably inevitable that impact deposits-possibly bearing spherules-will someday be discovered on the surface of Mars. If so, then the important question that must be answered in the course of in situ lander observations becomes: What are the characteristic features of spherule-bearing units produced by major impact-generated base surges that allow their identification? Unfortunately, descriptions of spherule-bearing deposits produced by impact with projectiles in the $10-\mathrm{km}$-diameter and larger size range, which are thus capable of producing aerially extensive ejecta layers, are rare in the literature (Graup 1981; Melosh 1989; Newsom et al. 1990; Pope et al. 1999, 2005; Warme et al. 2002; Masaitis 2003; Koeberl et al. 2007; Branney and Brown 2011). However, reinterpreted rock units in the western Lake Superior region now furnish examples of these types of deposits. In this case, the spherules formed as ash pellets, coated ash pellets, and accretionary lapilli.

The recent discovery of strata formed as a result of the Sudbury impact event (Addison et al. 2005) provides field-based evidence that can more accurately define the attributes of spherule-bearing deposits 
related to large collision events. At $1850 \mathrm{Ma}$ (Krogh et al. 1984), an object, probably in excess of $10 \mathrm{~km}$ in diameter, struck the edge of the Superior Province in the area that is now Sudbury, Canada. The impact produced the second largest known crater on the surface of the Earth (Earth Impact Database 2004, Spray et al. 2004), propelling an immense amount of material into the atmosphere. The region 400 to $900 \mathrm{~km}$ west of the impact site consisted of a peneplained terrain that was subaerial over most of its extent, with lithified carbonate and chert bedrock (Fralick and Burton 2008). It was possibly flooded with very shallow marine conditions in its western portions. The ejecta cloud swept across this setting, entraining locally derived material (Addison et al. 2010). In places, the impact layer deposited by this base surge was altered by possible tsunami activity (Pufahl et al. 2007), subaerial reworking, and diagenesis (Fralick and Burton 2008), and, 15 million years later, it was buried by marine sediments (Addison et al. 2005).

We have developed a facies model for the deposits associated with very large impacts based on the Sudbury ejecta blanket. This model is suitable for comparison to the spherule-rich deposits observed by the Opportunity rover at Meridiani Planum, Mars, and at other possible future planetary occurrences. The spherule-rich deposits at Sudbury indicate strong hydrodynamic sorting of grain size, and development of specific relationships between grain types and associated sedimentary structures such as cross-bedding.

\section{SUDBURY IMPACT DEPOSIT FIELD DESCRIPTIONS}

\section{Overview}

The Sudbury impact deposit was first discovered and documented in Ontario and Minnesota by Addison et al. (2005) (Fig. 1). Subsequently, other areas containing the layer have been identified (Pufahl et al. 2007, Jirsa 2008, Addison et al. 2010, Cannon et al. 2010). Over 20 outcrops and cored intervals through the impact-generated deposits, over an area of approximately $50,000 \mathrm{~km}^{2}$, were examined for this study. The layer is extremely laterally variable, ranging from totally absent in some locations to tens of meters thick in others. Locations separated by only a few hundred meters can be composed of different materials with contrasting textures and sedimentary structures. Even with these limitations, the outcrops and cored holes through the deposit provide abundant information on sedimentary structures, textures, and architectural organization of subaerially deposited spherules (accretionary lapilli) formed by the large impact event. For the sake of brevity, the term accretionary lapilli, as used here, includes ash pellets, coated ash pellets, and accretionary lapilli (see classification of Brown et al. 2010, Branney and Brown, 2011). All sites described contain a mixture of these three types of ash aggregates.

The Sudbury impact deposit includes all strata containing material that was moved laterally due to the impact event. Not all successions through the Sudbury impact deposit contain accretionary lapilli. Areas further than approximately $800 \mathrm{~km}$ from the impact site commonly do not contain accretionary lapilli. Sites closer to the crater generally do not contain accretionary lapilli in areas of the deposit where boulders of underlying lithologies or lapilli-sized devitrified glass are common. Sections containing abundant accretionary lapilli overlie disrupted bedrock, commonly either lithified carbonate layers or chert that was fractured by the impact-generated earthquake (Addison et al. 2010). At many locations, a zone of displaced rubble, which may contain boulder-sized clasts, immediately overlies the fractured basement, separating it from the lapilli-bearing units.

The impact-produced deposit may contain: (1) pebble- to sand-sized devitrified glass, where the larger pieces are commonly vesicular; (2) accretionary lapilli with diameters of 3 to $20 \mathrm{~mm}$; (3) pebbles to boulders of predominantly locally derived chert and carbonate; (4) unshocked quartz and feldspar grains; and (5) quartz with planar deformation features (PDFs) (Addison et al. 2010). The deposit also is associated with highly elevated amounts of iridium (Pufahl et al. 2007).

Three outcrop areas containing well-developed ejecta-bearing successions with accretionary lapilli are described in detail here. These were chosen because they are typical of the range of accretionary lapilli-bearing units that exist throughout the region.

\section{Site \#1}

The Connors Creek site (site \#1; Fig. 1) is located in the western portion of the Dead River Basin, near Marquette, Michigan (Cannon et al. 2010). A curving outcrop here allowed a series of sections to be compiled from the underlying basement to the top of the accretionary lapilli-rich layer (Fig. 2). In this outcrop, the Sudbury impact assemblage rests on chert, which is highly fractured in places. The lowermost impact-generated bed consists of matrix-supported, rounded to angular, granule- to pebble-sized chert fragments in coarse to very coarse sand. The sand is composed of: (1) devitrified glass, some of which is vesicular (Cannon et al. 2010); (2) chert grains; and (3) quartz grains. The pebbles, and more rarely up to boulder-sized clasts, are randomly orientated in this matrix. An irregular contact with protruding pebbles is draped by the overlying coarse- to very coarsegrained, parallel-laminated, pebble-bearing sandstone, which is interstratified with well-sorted, medium-grained sandstone. The coarser sandstone beds are, in places, laterally discontinuous, lensing out into the surrounding medium-grained sandstone. The bed boundaries in the upper portion of this sandy succession become undulatory in places, and erosive truncations show an upward increase in abundance. Some downcutting bed boundaries have their shapes mimicked by overlying beds, creating a succession of curving in-phase bed forms. This assemblage of bed forms is somewhat similar to the progression of upper-flow-regime, parallel-lamination to type $\mathrm{V}$ and type III dunes described by Schmincke et al. (1973, see their Fig. 6) from base surge deposits in the Laacher See area of Germany.

The first appearance of accretionary lapilli generally occurs as oneclast-thick stringers or small lenses, of 1.2-cm-diameter lapilli, in the sandstones. This is overlain by beds of clast-supported accretionary lapilli alternating with beds of coarse-grained sandstone with some isolated, matrix-supported accretionary lapilli (Fig. 2A, C, and E). Both textures are parallel-laminated to undulatory parallel-laminated (Fig. $2 \mathrm{E})$. The tops of lapilli protrude into overlying sandstones, whereas the tops of the sandstones are smooth and flat. The matrix in the accretionary lapilli layers is commonly coarser grained than the adjacent sandstone, being dominated by very coarse-grained sand to granules (Fig. 2F). Accretionary lapilli beds are laterally transitional into very coarse-grained sandstone layers, and sand stringers and lenses exist in some lapilli beds (Fig. 2E). The accretionary lapilli themselves decrease in size upward through the unit from $0.7 \mathrm{~cm}$ in the middle of the accretionary lapilli-bearing assemblage to $0.4 \mathrm{~cm}$ at the top. The upper portion of this unit contains bundles of laminae separated by low- to moderate-angle erosive scour surfaces backfilled with accretionary lapilli and sand-dominated beds. Backfilling strata fill scours, building in an upstream direction, and extend laterally outside the scour on the downstream side to drape the underlying scoured beds (Fig. 2C, D). This layering is similar to what Schmincke et al. (1973) termed "dune types III and IV."

The uppermost portion of the accretionary lapilli-bearing interval is denoted by the increased abundance of coarse-grained, upper-flowregime, parallel-laminated sandstone beds in which lapilli are restricted to thin, discontinuous beds, lenses, and single-clast-thick stringers in the sandstones. In places, 10- to 40-cm-thick, festoon (trough) crossstratified sandstones fill erosive cuts into the lapilli-bearing units (Fig. 2A, B). This is overlain by a massive, coarse-grained sandstone bed with chert pebbles and cobbles and scattered lapilli. The bed is at least $30 \mathrm{~cm}$ thick, limited by the upper extent of the outcrop. X-ray 


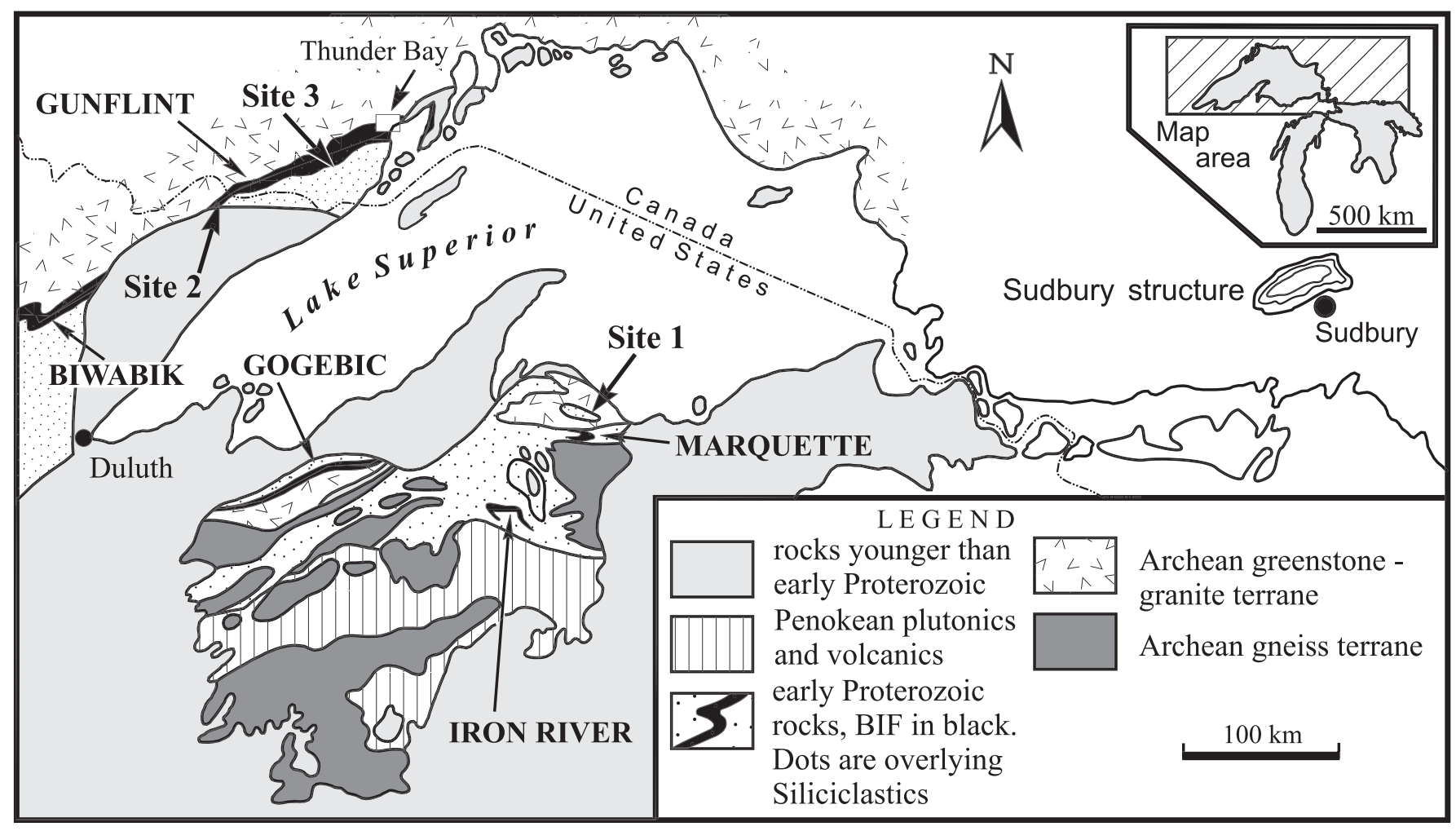

FIG. 1.-Location of the Sudbury structure, the remnant of the crater formed by the impact, and the three outcrop sites discussed in detail in the text. The oval outline of the Sudbury structure was caused by deformation during the Grenville Orogeny. The layer formed by the impact occurs at the contact between the iron formation, in black, and a thick succession of overlying shales and turbiditic sandstones (small dots).

diffraction (XRD) studies have shown that the lapilli are composed of $45-60 \%$ quartz, $15-30 \%$ dolomite (possibly secondary), and lower concentrations of microcline, plagioclase, muscovite, and chlorite (Cannon et al. 2010).

Another outcrop of the Sudbury impact deposit exists approximately $200 \mathrm{~m}$ from the one described previously (Cannon et al. 2010). Here, the lower portion of the impact deposit is not exposed, and the succession begins with $24 \mathrm{~cm}$ of upper-flow-regime, parallellaminated, medium- to coarse-grained sandstone. This is followed by $26 \mathrm{~cm}$ of massive, coarse-grained sandstone with scattered, angular to well-rounded, pebble-sized chert fragments. A couple of round pebbles may be accretionary lapilli, approximately $0.7 \mathrm{~cm}$ in diameter. The overlying bed is $50 \mathrm{~cm}$ thick, and it is composed of coarse-grained sand to granules organized into what is probably one set of moderate-angle, sigmoidal-shaped cross-stratification. Scattered pebbles and rare accretionary lapilli, in matrix-support, occur at the base of this bed. The uppermost bed in the succession consists of parallel-laminated, medium- to coarse-grained sandstone, approximately $80 \mathrm{~cm}$ thick. Bedded chert overlies the ejecta deposit and represents commencement of non-ejecta-related sedimentation.

\section{Site \#2}

Site \#2 occurs southwest of Gunflint Lake, Minnesota, approximately $750 \mathrm{~km}$ from the impact crater (Jirsa 2008) (Fig. 1). Deposits here appear to be consistently thicker than in other areas, even though these sites are more distal than those in Michigan and Ontario. The impact deposits at sites further away from the crater than Gunflint Lake are much thinner, and lapilli are only rarely present. This led Addison et al. (2010) to hypothesize that the Gunflint Lake deposits may represent thick ramparts, as described for end-of-flow Martian base surge deposits (Kenkmann and Schonian 2006, Osinski 2006, Mouginis-Mark and Garbeil 2007). Most of the deposit at Gunflint Lake is made up of disorganized-bedded boulder breccia, with clasts composed of lithologies present in rocks of the underlying Gunflint Formation. The boulder breccia is commonly overlain by a 10 to 20 cm-thick, matrix-supported pebble breccia to massive, pebbly sandstone. Rare, scattered accretionary lapilli occur in this unit. The pebble breccia is overlain in some sections by accretionary lapilli beds with clast-supported textures. These fill shallow scours in the top of the pebble breccia, or deeper scours that remove strata all the way down to the boulder breccia. The base of the scours is commonly overlain by a 1 -cm-thick layer of coarse-grained sandstone, followed vertically by the accretionary lapilli. In other locations, in an area covering a few square kilometers, layers of upper-flow-regime, parallel-laminated, medium-grained sandstone separate the breccia from the accretionary lapilli-rich beds (lapillistone) (Fig. 3). In places, cross-stratified accretionary lapilli fill scours into the sandstone at the base of the lapillistone, giving a paleocurrent direction of $260^{\circ}$. The down-current bearing from Sudbury to Gunflint Lake is $280^{\circ}$. At other locations, where individual smaller scours at the base of the lapillistone are not present, the basal, clast-supported lapillistone bed drapes a shallow erosive scour (Fig. 3). The lowermost accretionary lapilli-rich bed is massive-textured, as are overlying accretionary lapilli-rich beds, except where rare, small-scale, low-angle cross-stratification dipping toward $060^{\circ}$ is visible. The basal bed is generally less than $15 \mathrm{~cm}$ thick and is succeeded upward by $1-$ to 5 -cm-thick accretionary lapilli beds alternating with coarse- and medium-grained sandstone beds (Fig. 3). The sandstones are parallel-laminated and composed of a mixture of locally derived chert and iron formation grains and more far-traveled 


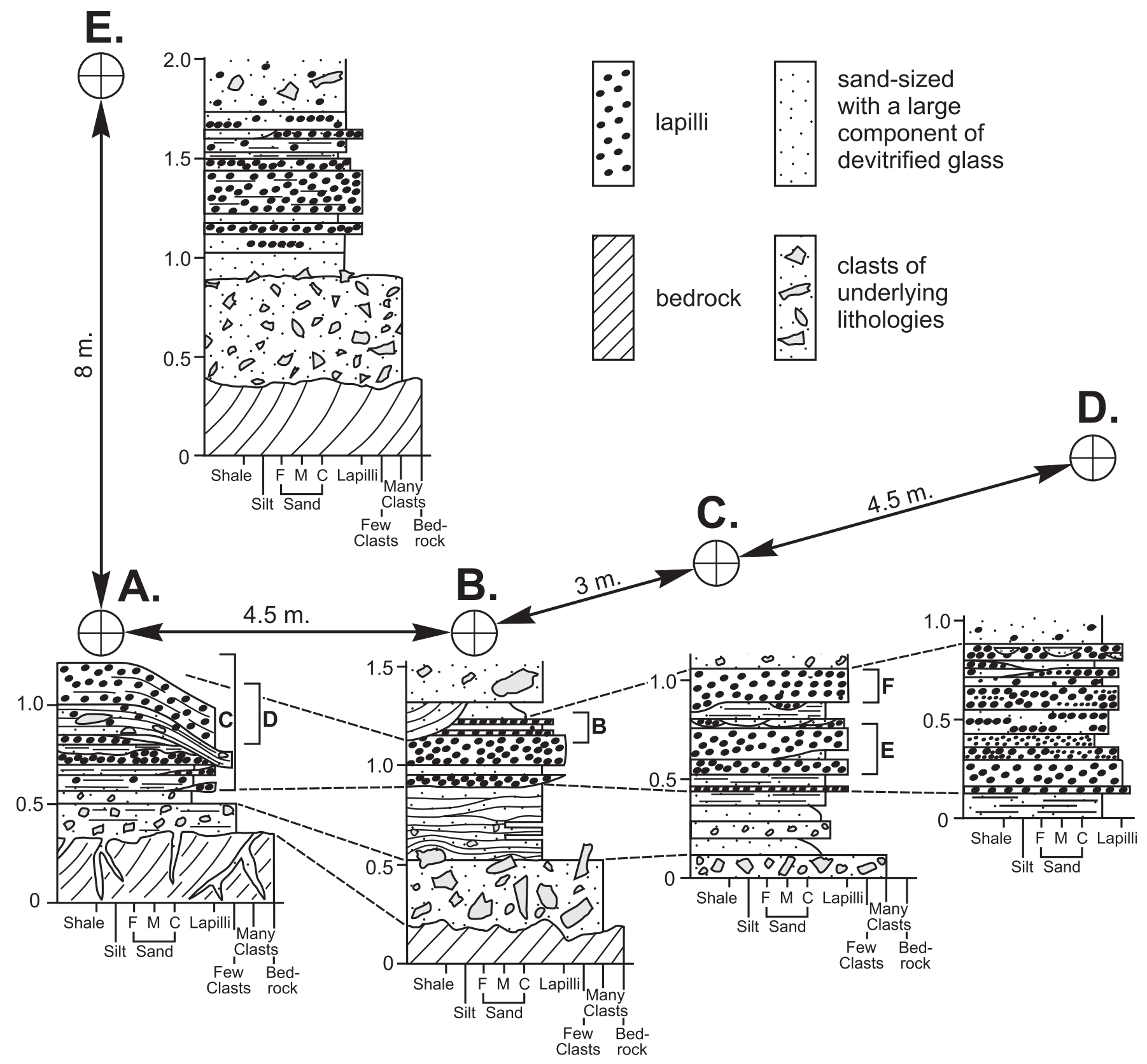

FIG. 2.-Left) Stratigraphic architecture of the units present at site \#1. The upper sand-rich portion of the impact layer is not present at this outcrop. Locations of photographs are denoted. Right) Photographs of units present at site \#1. A) Photograph of stratigraphic section B. B) Enlargement of the upper left of outcrop in A showing a trough-shaped erosive scour cutting interlayered parallel- to wavy-laminated accretionary lapilli and sand-rich beds, and filled by trough cross-stratified sandstone. Flow is from right to left. The oval shape of the lapilli is due to deformation in this area. Coin is $26 \mathrm{~mm}$. C) Photograph of the upper half of section A. D) Enlargement of the upper central portion of C showing parallel- to wavy-laminated accretionary lapilli and sand-rich layers that are truncated and overlain by an antidune-like structure similar to Schmincke et al.'s (1973) dune type III. The uppermost laminations visible in the upper right of C may represent an upward transition to chute and pool deposition, though the extent of the outcrop is not large enough to discern this reliably. This would denote either increasing velocity and/or decreasing flow depth with time, resulting in upper-flow-regime bed forms progressing from steady flow to shooting flow with hydraulic jumps. Flow is from right to left. Coin is $19 \mathrm{~mm}$. E) Lapilli-dominated area of the outcrop. The wavy lamination, especially visible in the upper central portion of the photograph, probably reflects deposition in the transitional zone from plane bed to antidunes. Coin is $26 \mathrm{~mm}$. F) Polished slab showing accretionary lapilli- and coarse sand-bearing beds. Note that the matrix of the lapilli beds is coarser than the sandstone beds, reflecting higher velocity and shear stress conditions during deposition of the former. 

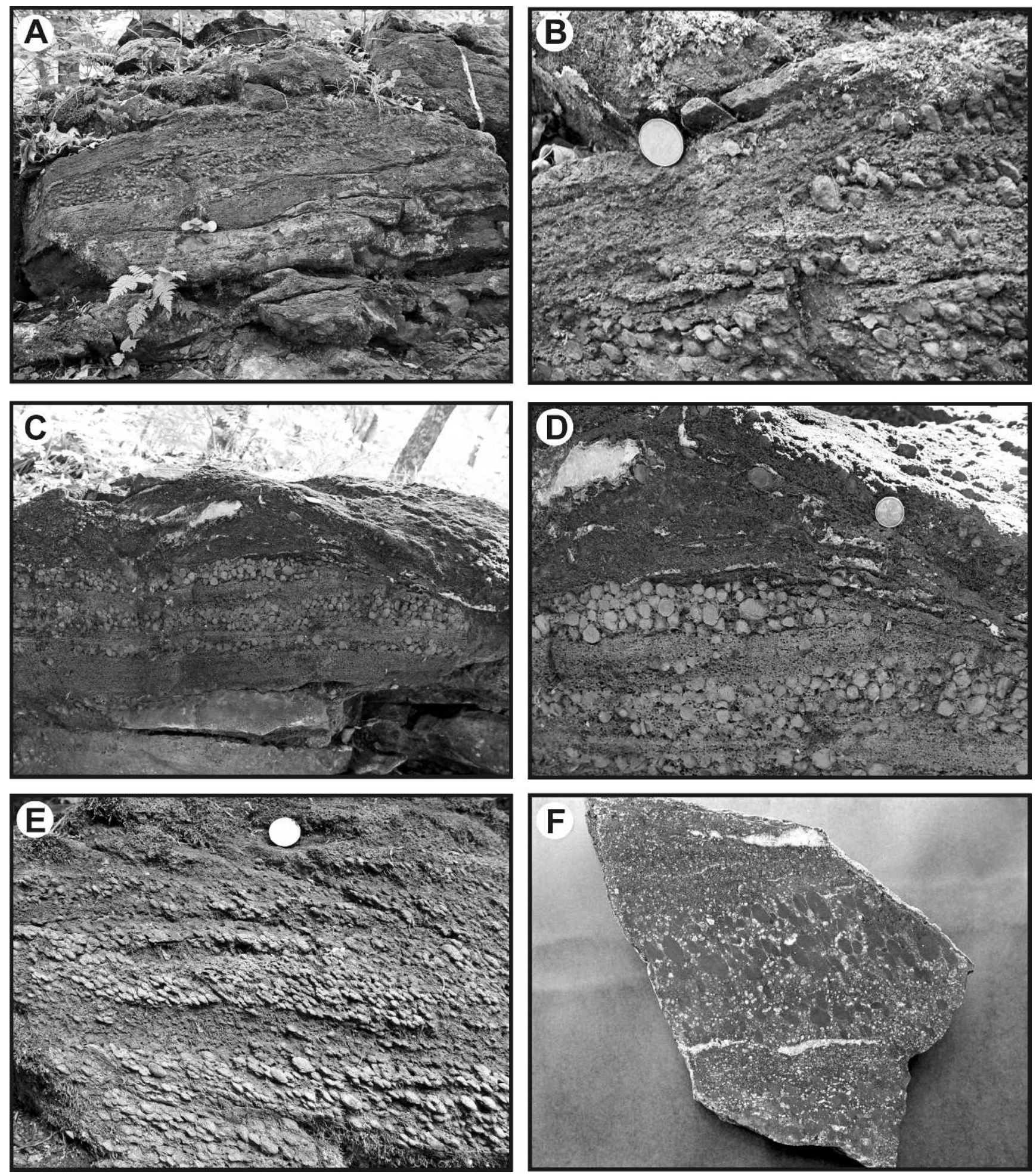

Fig. 2.-Continued. 


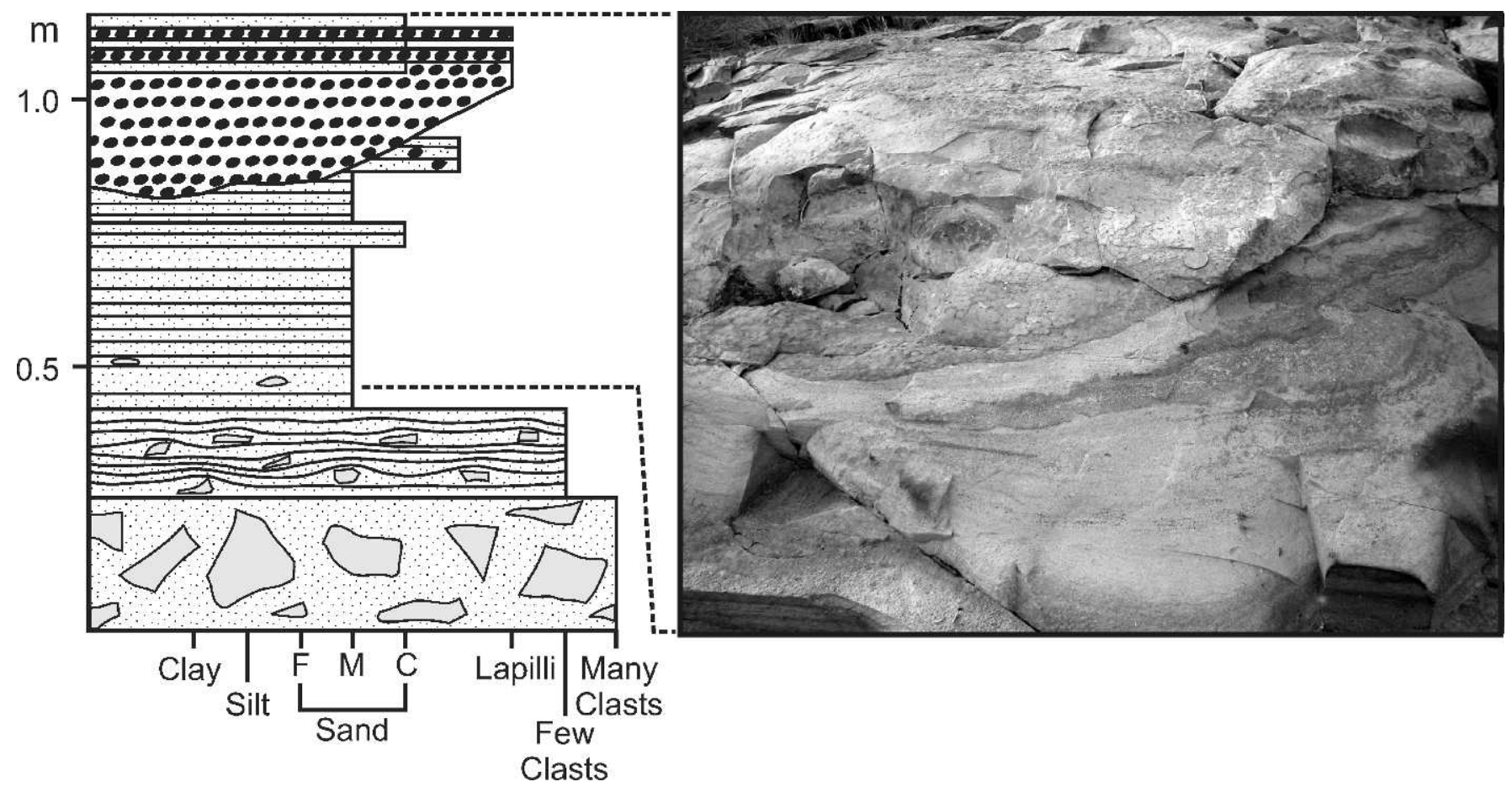

FIG. 3.-Section through one of the outcrops in the area demarked site \#2 on Figure 1. Note that one fining-upward succession is erosively truncated by an accretionary lapilli-rich second fining-upwards succession.

grains of devitrified glass. Accretionary lapilli in the bed at the base of the lapilli-rich interval average 0.7 to $0.8 \mathrm{~cm}$, and those higher in the section and interbedded with sandstone are 0.2 to $0.4 \mathrm{~cm}$. The sandstone beds become more dominant in the next few decimeters. Here, they are medium- to fine-grained, with stringers and patches of small accretionary lapilli. Some beds are massive with abundant, isolated lapilli. Parallel-lamination to undulating parallel-lamination is common in the non-massive beds. An approximately $10 \mathrm{~cm}$ interval of thinly laminated siltstone caps the impact deposit.

\section{Site \#3}

Site \#3 is located west of Thunder Bay and is described by Addison et al. (2010) as the Highway 588 site (Fig. 1). The outcrop exposure here was blasted during road improvements, which led to an abundance of large blocks of the impact deposit, providing good threedimensional views (this is termed site \#3A). To add to the database, two cored holes were drilled through the unit approximately $200 \mathrm{~m}$ from the road exposure (site \#3B).

The main exposure consists of lithified carbonate grainstones and stromatolites that were erosively planed off and are overlain by impactderived material (Fig. 4A-C). Scattered pebbles to boulders of the underlying lithologies occur in the impact deposit (Fig. 4E). The lowest lapilli-bearing unit lies directly on the stromatolites and grainstones in places (Fig. 4A, D), but in other locations, it is separated from the substrate by a thin bed of very coarse-grained sandstone with granules (Fig. 4C). The sandstone is also present in depressions in the bedrock surface and was scoured prior to deposition of the overlying lapillibearing unit (Fig. 4A, B). The lower 30-cm-thick bed of lapillistone appears massive in most samples, but a crude cross-stratification is present in some portions of the outcrop that are highlighted by more sand-rich partings dipping at approximately $30^{\circ}$ (Fig. 4D). The lapilli in this bed average $1.1 \mathrm{~cm}$ in diameter. Most lapilli have a clast- supported texture; however, areas of matrix-supported textures do exist. Portions of the bed also have common lithic lapilli, composed of amygdaloidal, devitrified glass, and pebbles of underlying lithologies, mainly black chert. This bed is overlain by $15 \mathrm{~cm}$ of interstratified upper-flow-regime, parallel-laminated accretionary lapilli beds and coarse-grained sandstone beds. These layers form lenses that taper out laterally, commonly over 1 to $2 \mathrm{~m}$. The lapilli here average $0.8 \mathrm{~cm}$ in diameter. The uppermost unit in this outcrop is $20 \mathrm{~cm}$ thick and consists of 1- to 3-cm-thick beds of parallel-laminated, coarse- to medium-grained sandstone. Strata in the lower $8 \mathrm{~cm}$ of this unit contain stringers of accretionary lapilli associated with laminae of coarser sandstone with some scattered, isolated lapilli (Fig. 4F). No lapilli were observed in the upper portion of this sandstone succession.

The drill hole, though only $200 \mathrm{~m}$ away, intersected a different assemblage (Fig. 5). The impact deposit here lies on cherts forming the Gunflint bedrock. The lower two thirds of the deposit exhibit inverse, coarse-tail grading, going from very coarse-grained, granule-bearing sandstone at the base to pebbly, granule-rich, very coarse-grained sandstone with scattered accretionary lapilli. The upper third of the core is normally graded from the pebbly sandstone to a mediumgrained sandstone. No sedimentary structures were observed, except for an indistinct parallel lamination in the upper $5 \mathrm{~cm}$ of the core.

\section{MARTIAN SPHERULE-BEARING STRATA}

For the first time in the history of the exploration of Mars, the observation by Opportunity of ancient sedimentary processes recorded in the strata preserved at Meridiani allowed a fresh approach to understanding the early history of surface processes on Mars. This approach implements standard techniques used in analysis of terrestrial strata. Reconstruction of depositional processes is based on the analysis of suites of physically produced sedimentary structures along with observations of other textural attributes such as grain size, sorting, 

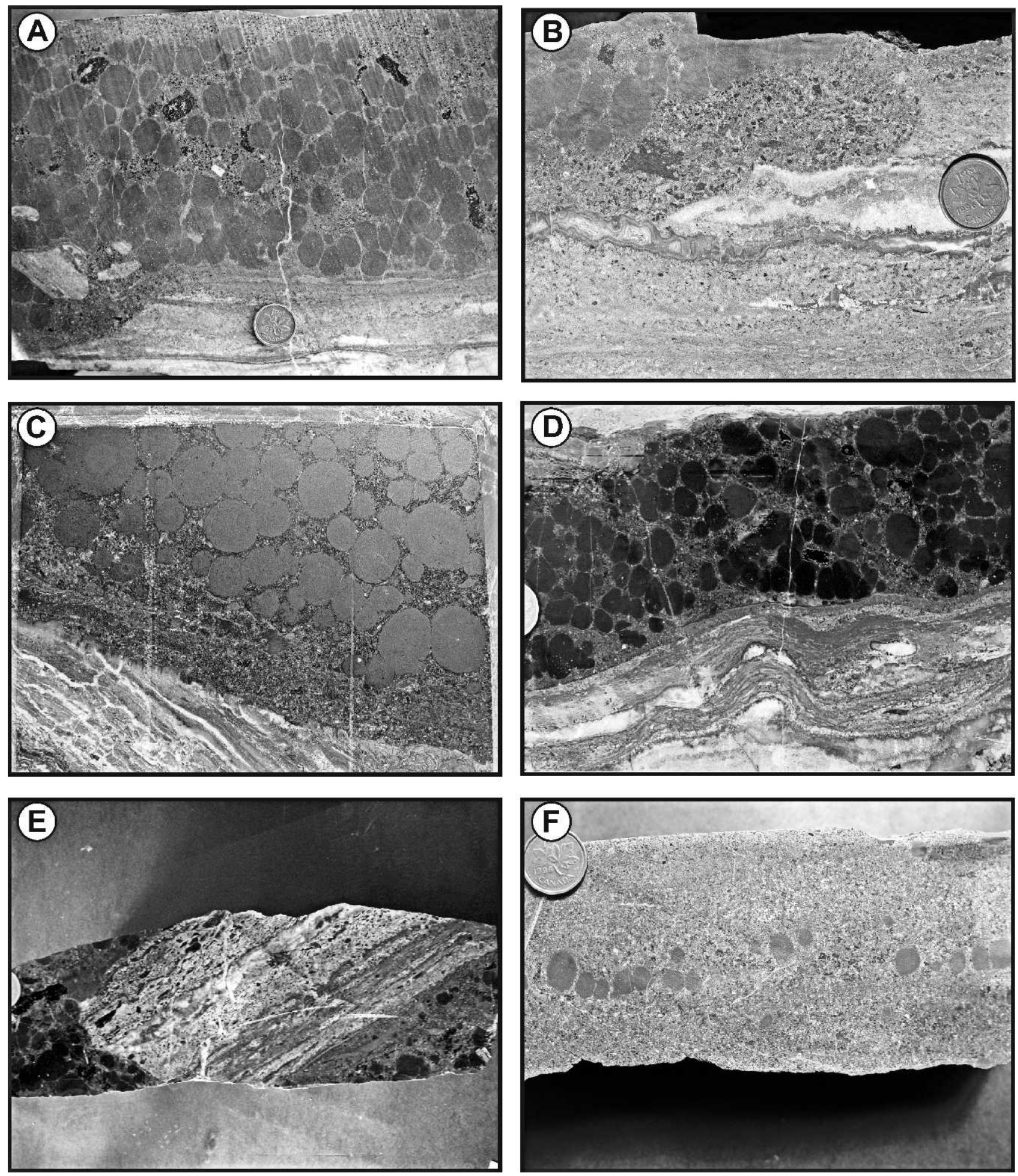

FIG. 4.-Photographs of cut slabs from site \#3A. A) Erosively scoured bedrock composed of Gunflint carbonate and chert overlain by the impact deposit. Very coarse-grained sandstone with granules fills the scour. Coin is $19 \mathrm{~mm}$. B) Another example of a scoured depression filled by a remnant of granule-rich sandstone. Note the very coarse-grained, granule-rich sandstone in the scour has a different grain size than the matrix of the overlying lapilli-rich bed. C) The truncated top of a hemispherical stromatolite overlain by a layer of very coarse-grained sandstone, which in turn is overlain by accretionary lapilli in clast-support. Slab courtesy of W. Addison. D) Lapilli directly overlying Gunflint carbonate bedrock. E) A large block of underlying bedrock encased in accretionary lapilli-rich ejecta. F) Coarse-grained sandstone, which lies above the more massive accretionary lapilli-rich bed (not present in this slab). Note the stringers of lapilli are associated with, and overlain by, coarser sand-sized material than that constituting the underlying layer. 


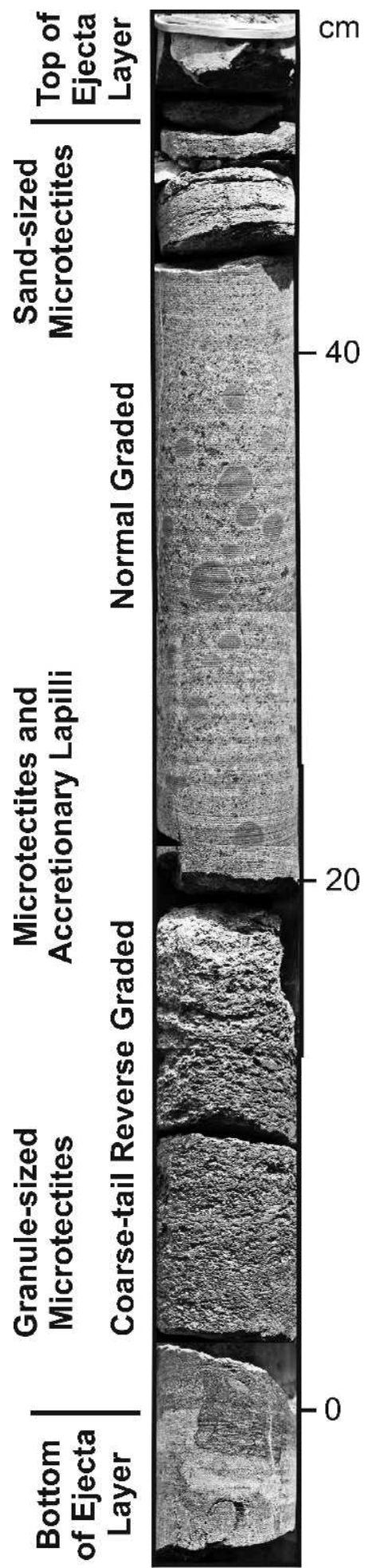

FIG. 5.-Drill-hole intersection with ejecta deposit from site \#3B.

and associated diagenetic features (cf. Leeder 1982). Detailed observations and measurements related to the sedimentology, stratigraphy, mineralogy, provenance, and diagenesis at Meridiani, Mars, have been previously reported (Squyres et al. 2004a, 2006b; Clark et al.
2005; Grotzinger et al. 2005, 2006; McLennan et al. 2005; Squyres and Knoll 2005; Edgar et al. this volume). Here, we summarize the key observations that relate to the physical emplacement of these sedimentary rocks for the purpose of comparison with the Sudbury impact deposit.

The Burns formation is the informal name given to the succession of well-sorted, moderately indurated sandstones (Grotzinger et al. 2005) preserved immediately beneath the surface of the Meridiani plains and examined in most detail at exposures in the vicinity and within Eagle, Endurance, Erebus, and Victoria craters. Regional geology suggests that the deposit is of late Noachian age and thus likely in excess of 3.5 Ga. Detailed stratigraphic measurements (Fig. 6) and sedimentological observations (Fig. 7) generally support a model whereby eolian and locally subaqueous processes deposited these sediments (Fig. 8). The Burns formation has been divided into three stratigraphic units (lower, middle, and upper), and three major sedimentary facies associations have been identified (Grotzinger et al. 2005, Edgar et al., this volume):

1. Facies A is composed of large-scale cross-bedded well-sorted sandstones. This facies is interpreted to represent a migrating dune system of unknown extent that was deposited under dry conditions such that the sediment was noncohesive and thus transported in migrating dune fields. Bed set thicknesses suggest moderately large dunes in excess of $2 \mathrm{~m}$.

2. Facies B is planar-laminated to low-angle cross-stratified, wellsorted sandstones. This type of stratification results from sediment limitation, forming low-relief bed forms produced by migrating impact ripples. In Endurance crater, the contact between the dune and overlying sand sheet facies marks the boundary between the lower and middle stratigraphic units. This important stratigraphic boundary, termed the Wellington contact, is interpreted to be a deflation surface formed where the groundwater capillary fringe limited erosion of previously deposited dune sediments. This facies is interpreted as an interdune sand sheet deposit. Smith and Katzman (1991) describe eolian deposits from the Jemez Mountains volcanic field, New Mexico, that are similar to facies A and B. They emphasize that the styles of stratification in the eolian deposits are distinct from those of interbedded base surge deposits, making their differentiation possible.

3. Facies $\mathrm{C}$ is centimeter-scale trough (or "festoon") ripple crosslamination, diagnostic of subaqueous current transport in the lower flow regime. At Endurance and Eagle craters, this facies is found in the upper part of the upper unit of the Burns formation and marks where the groundwater table breached the surface and wind-driven subaqueous currents transported the sediment. Centimeter-scale trough cross-lamination is particularly well developed at Erebus crater, where additional features suggestive of desiccation also are present. Polygonal patterns of small cracks are interpreted to have formed during multiple wetting and drying events, and soft sediment deformation features are consistent with sediment liquefaction. This facies is interpreted as a wet to evaporitic interdune environment.

All facies present in all craters studied by Opportunity contain spherules. Comparison of their size and spacing has been presented by McLennan et al. (2005) and Edgar et al. (this volume). Spherules in the Burns formation have relatively uniform shape and size (Fig. 9). At Eagle and Endurance craters, they have a rather uniform size distribution of about $4 \mathrm{~mm}$ average and are almost perfectly spherical (McLennan et al. 2005). Spherules at Victoria crater are smaller, with an average diameter of about $1 \mathrm{~mm}$ (Edgar et al. this volume). At all outcrops observed to date, the spherules do not disrupt lamination and are highly dispersed relative to bedding, so they are not observed to concentrate along bedding planes or scour surfaces (Fig. 10). All factors considered, the Burns spherules are most likely to have formed 


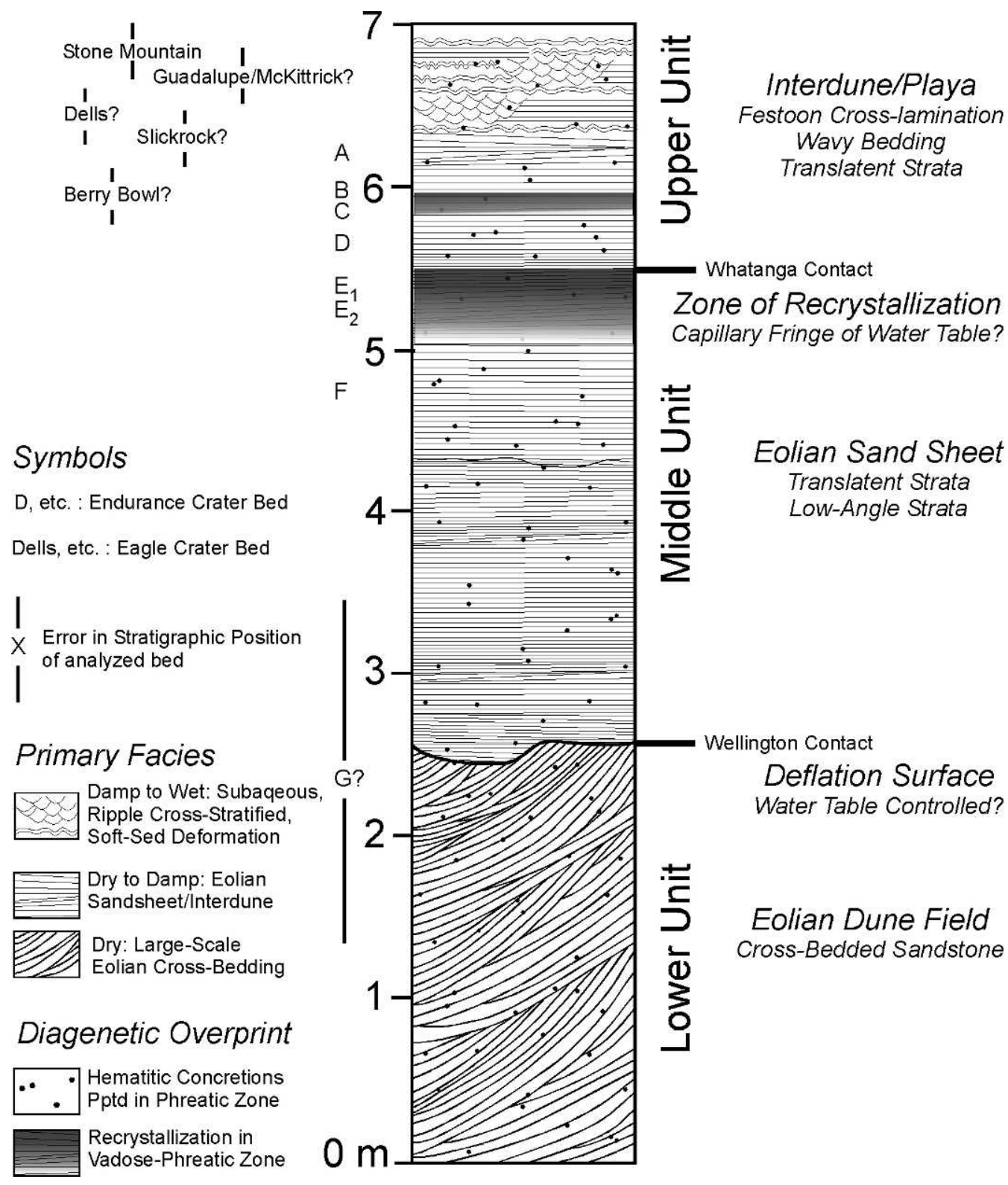

Fig. 6.- Stratigraphy of the Burns formation exposed at Burns cliff and within Eagle crater, Meridiani Planum. Names and letters on the left side denote the approximate stratigraphic locations of key rocks and targets. Sedimentological interpretations of the three stratigraphic units are shown on the right hand side of the column. See text for further discussion. From Grotzinger et al. (2005).

as diagenetic concretions (McLennan et al. 2005). However, see the following section for a discussion of alternatives.

\section{DISCUSSION}

Though direct observation of the events triggered by a large impact on a terrestrial planet has never been made, insight into the sediment dispersal dynamics can be gained from the literature on explosive volcanic eruptions and nuclear tests. Surges generated by subaerial, pyroclastic eruptions are low-concentration, high-velocity currents, which are dominated by high degrees of turbulence (Carey 1991, Orton 1996). The stratification and sorting characteristics of volcanic base surge deposits are largely determined by the particle concentration and velocity profiles across the flow-boundary zone from which the lithofacies aggrades (Branney and Kokelaar 2003). The particle concentration and velocity profiles follow clear trends based on proximity to the source and relative position within the flow, producing predictable patterns in stratification and sorting. Deposits formed from these flows show distinct proximal to distal and bottom to top changes consistent with decreases in flow velocity and sediment accumulation rate (Chough and Sohn 1990). In more vent-proximal areas and within valleys or channels, where sediment accumulation rates from suspension are high, thicker, massive, and coarser-grained deposits accumulate (Crowe and Fisher 1973, Chough and Sohn 1990, Druitt 1992, Orton 1996). As the cloud loses material and sediment concentration declines, deposition from the traction carpet dominates, 


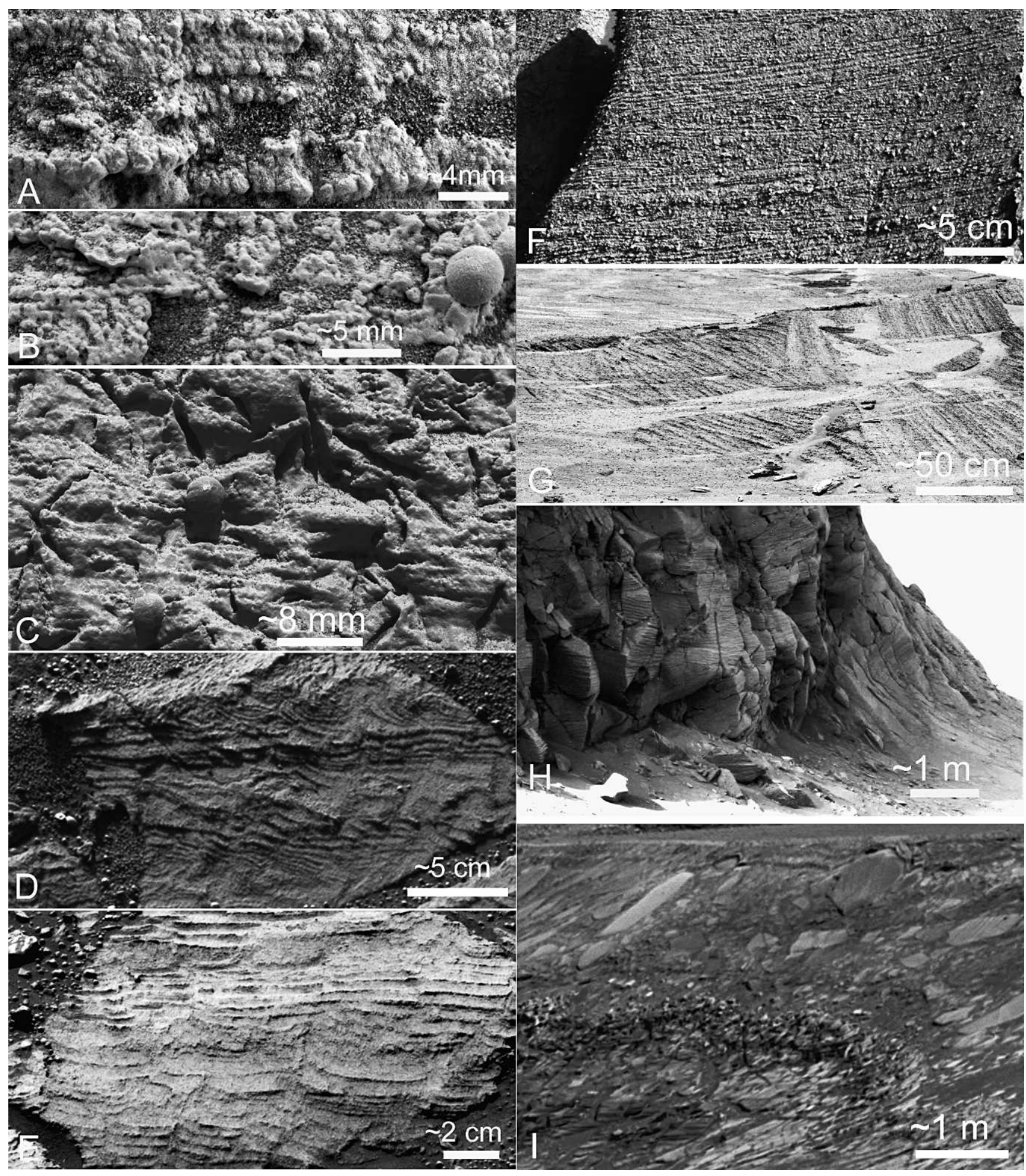

FIG. 7.- Sedimentologic observations that constrain the environment of deposition for the Burns formation. See Grotzinger et al. (2005), Grotzinger et al. (2006), McLennan et al. (2005), Metz et al. (2009), and Edgar et al. (this volume) for further descriptive and interpretive details. A) Microscopic Imager (MI) image showing distinct grains that form laminated sandstones ("Flatrock," Eagle crater) of the Burns formation. Grains range in size from 0.1 to $1.0 \mathrm{~mm}$, are moderately well rounded, and are well sorted into discrete laminae. The excellent size sorting on the scale of individual laminae is strongly suggestive of migrating eolian impact ripples. The image (1M131912465) was acquired on sol 042. B) MI image showing effects of early cementation and recrystallization, visible in the center left ("Algerita," Eagle crater). Note the set of three or four laminae, expressed by fused grains. At center right, the effects of recrystallization on destruction of primary fabrics are well illustrated by 
and stratified deposits form (Schmincke et al. 1973, Chough and Sohn 1990, Carey 1991, Orton 1996). Thus, deposits progress from massive to well stratified, both outward from the vent - though local topography complicates this (Schmincke et al. 1973, Wilson and Walker 1982, Druitt 1992, Brown et al. 2010) - and upward through the deposit. Grain size also generally decreases in these two directions, and sedimentary structures change from higher- to lower-velocity bed forms (Crowe and Fisher 1973, Chough and Sohn 1990).

In the deposits formed by the Sudbury impact event, basal, disorganized, pebble to boulder breccias, composed of underlying lithologies, commonly with little to no lithic or accretionary lapilli, overlie a bedrock surface that is, in places, severely jointed. The nearsurface rock layers were fractured and rotated by the strong earthquake produced by the impact (Addison et al. 2010). The presence of abundant boulders over $1 \mathrm{~m}$ in diameter that were entrained by the flow indicates that the leading edge of the base surge was traveling at very high velocity. Additionally, the shock wave (see Wohletz et al. 1984) produced by the impact may have swept some of the pre-earthquakearrival, surficial debris into depressions prior to entrainment by the base surge. The breccias commonly are coarse-tail graded upward (Addison et al. 2010), indicating decreasing flow velocities. They are overlain by upper-flow-regime, parallel-laminated sandstones composed of angular, aphanitic grains of various sericite- and chloritedominated lithologies (Cannon et al. 2010), probably representing devitrified glass. At site \#1, where this sandstone is best exposed, all bed forms are upper flow regime with an upward progression in some sections from parallel lamination to undulatory layering. Undulatory layering associated with parallel lamination similar to that present in the Sudbury impact deposits has been described from base surge deposits in the Laacher See area (Schmincke et al. 1973), at Songaksan mount (Chough and Sohn 1990), and at Cora Maar volcano (Gencalioglu-Kuscu et al. 2007).

The absence of accretionary lapilli in the lower sandstones may reflect processes similar to those proposed to operate in groundhugging pyroclastic density currents developed during eruptions on Tenerife (Brown et al. 2010). Here, the absence of accretionary lapilli in the basal portion of the deposits is attributed to a two-stage process. Ash pellets formed in the uppermost lofted, moist, and cool parts of the plume above the base surge. They then dropped into the high-velocity, ground-hugging turbulent current, accreted concentric layers, and were sedimented (Brown et al. 2010, Branney and Brown 2011). The leading front of the ground-hugging flow advanced in front of the overlying, billowing ash cloud and, thus, did not receive ash pellets to transform into accretionary lapilli.

The thickness of the lower sandstones is probably controlled by fluctuations in velocity and concentration of sediment in the highly turbulent flow. At site \#3A, where these sandstones are mostly limited to low-velocity zones in depressions and behind obstacles, overall flow conditions did not fall within the depositional realm until the main upper ash plume had advanced over the area and accretionary lapilli began accumulating. At site \#2, the flow conditions accommodated sand and granule deposition from the leading edge of the surge, but arrival of the upper ash plume over this area was accompanied by a change in conditions promoting erosion of an unknown thickness of the sand. Deposition of accretionary lapilli filled this broad scour surface and individual smaller scours superimposed upon it. Crossstratification, consisting of alternating accretionary lapilli laminae and laminae of sand-sized material, developed during infilling of the scours and behind obstacles, such as boulders or small bedrock promontories. At site \#1, no noticeable erosion occurred between deposition of the sandy succession and the overlying accretionary lapilli. Site \#3B has a gradual transition as well, but in a massive assemblage of sediment.

The accretionary lapilli-rich units overlying the upper-flow-regime, parallel to undulatory beds of sand- to granule-sized material possess many of the attributes of the sandy succession. The common parallellamination and rarer development of cross-stratification dipping toward the impact site (similar to type III and V dunes of Schmincke et al. [1973], which were interpreted as antidunes, i.e., structures developed at higher velocities than parallel-lamination and in association with a hydraulic jump) indicate that the lapilli-bearing units were deposited under upper-flow-regime conditions. As in the underlying sand dominated beds, this type of layering developed when sediment in suspension rapidly dropped into the traction carpet and was deposited. Changes in velocity of the highly turbulent flow resulted in deposition of accretionary lapilli, with very coarse-grained sand, granules, and small pebbles forming the matrix, interbedded with

a halo, which envelops a hematitic spherule interpreted as a concretion. Note complete loss of primary fabric and development of blocky, interlocking crystals. The image was acquired on sol 028. C) MI mosaic showing both diagenetic concretions (positive relief) and molds after diagenetic minerals (negative relief). Note distinct geometric shapes of crystal molds, which crosscut primary lamination. The images were acquired on sol 029. D) Pancam image of trough (or "festoon") cross-lamination (upper "Overgaard," Erebus crater). Small-scale trough crosslamination is interpreted to have formed in low-velocity subaqueous flows. This image was acquired on sol 716. E) Pancam image of probable desiccation cracks and soft-sediment deformation features ("Skull Valley," Erebus crater). Cracks crosscut lamination, some oblique to bedding. Note characteristic upward-deflected laminae along crack margins; termination of prominent crack in center of rock at a discrete bedding plane; and truncation of upward-deflected laminae along discrete bedding planes in center and upper parts of rock. This image was acquired on sol 713. F) Pancam image of low-angle cross-stratification featuring well-developed pinstripe texture, which has likely formed due to differential cementation of eolian wind ripple stratification ("Tipuna," Endurance crater). The Tipuna outcrop represents the uppermost 30-40 cm of the Burns middle unit. The image was obtained on sol 307, and a larger version is shown in Figure 10. G) Pancam image of the contact between the lower and upper units of the Burns formation. Bedding dips steeply to the right, and the trace of the contact runs nearly vertically through the image and is to the right of the center of the image. Below the contact, large-scale cross-bedding forms a bed set at least $2 \mathrm{~m}$ thick that was likely formed by migrating eolian dunes and consists of strata that are steeply inclined relative to the truncation surface. The contact- $-\mathrm{a}$ truncation surface - is interpreted to represent deflation of the dune field down to the level of the groundwater table. The image was acquired on sol 288. H) Pancam image of large-scale cross-bedding in the cliffs of Victoria crater, along the west-facing wall of Cape St. Mary. This cross-stratification is also diagnostic of migrating eolian dunes, as indicated by the presence of meter-scale scours and wedge-shaped sets. The image is part of a mosaic acquired during sols 970-991. I) Pancam image of ejecta blanket deposited on Burns formation bedrock at Victoria crater, along the east face of Cabo Frio. The blanket consists of coarse block breccia and is capped by a stratified upper unit, which drapes protruding breccia blocks. It was formed by ejection of bedrock during the impact event that created Victoria crater. The image is part of a mosaic acquired on sol 952. 
coarse-grained sandstone. A decrease in size of the accretionary lapilli up through this unit denotes a drop in flow competency, culminating in a sand-dominated succession with accretionary lapilli concentrated as stringers at the base of coarser sand-granule-dominated beds and, more rarely, isolated in massive beds. These massive beds with scattered accretionary lapilli probably formed as a result of an increase in the rainout of material from suspension, which will suppress the formation of parallel lamination (Arnott and Hand 1989). Further dropping of flow competency upward through the succession resulted in the development of lower-flow-regime bed forms (scour-fill festoon crossstratification, dunes, and sand waves). Only rare accretionary lapilli are found at the base of this sandstone unit, i.e., scattered accretionary lapilli along the top surface of the basal erosive scour underlying the sigmoidal-shaped cross-stratification at site \#1. Because of a large difference in mass between the lapilli and sand, the accretionary lapilli were probably remobilized from exposed accretionary lapilli layers and rolled in traction rather than transported into the area in suspension with the other material in the waning flow.

A general model for deposition of accretionary lapilli-bearing and related units can be developed using data collected from sections through the impact deposit (Fig. 11). This model does not reflect proximal to distal relationships, but rather decreasing energy level during sediment accumulation. Sites \#3A and \#3B are within $200 \mathrm{~m}$ of one another, yet their deposits are at opposite ends of the spectrum (Fig. 11). Work on volcanogenic base surges and ignimbrites has highlighted that local topography can exert an important control on the type and thickness of the sedimentary succession that accumulates (Schmincke et al. 1973, Wilson and Walker 1982, Druitt 1992, Brown et al. 2010, Branney and Brown 2011). It is envisaged that localized topographic differences also played an important role in defining the type of accretionary lapilli-bearing successions that developed in the Sudbury impact deposits. Examination of outcrops where basement topography is exposed confirms that thicker deposits of the basal breccia accumulated in bedrock lows, whereas adjacent higher levels were swept clean of debris and accumulated lithic lapilli-sized sediment. Although the basement topography at site \#3 is unknown, a similar scenario is plausible there.

Coarse-tail normal grading in the basal breccia (Addison et al. 2010) combined with the overlying parallel-laminated sandstone to form a powering down succession. Erosive truncation of the top of this unit at some locations indicates that there was an increase in competency prior to the arrival of the lofted portion of the flow where accretionary lapilli could form. The lofted portion of the ash cloud provided a source for the accretionary lapilli, which were sedimented by traction processes in the highly turbulent, basal surging flow. The coarser accretionary lapilli in beds deposited on the, in places, eroded top of the sandstones form the base of a fining-upward succession to small accretionary lapilli and finally sands, forming another powering down series of beds. This decrease in energy is also reflected in the upper-flow-regime bed forms in the accretionary lapilli-rich section, which are replaced upward by lower-flow-regime bed forms in the overlying sand-rich sediments.

The ejecta-bearing sediments exposed in the drill hole at site $\# 3 \mathrm{~B}$ are massive, except for parallel lamination in the uppermost fine-grained sandstones. Their inverse to normal grading is similar to some layers deposited from base surges in the volcanogenic Songaksan tuff ring (Chough and Sohn 1990). There, the inverse grading is related to dispersive pressure within a suspension or a traction carpet with a dilute, turbulent overriding surge (Chough and Sohn 1990). The normally graded portion was probably deposited from suspension. This depositional scenario may be applicable to site \#3B, but the lack of parallel lamination or other sedimentary structures also indicates that movement from suspension was not into a traction carpet, but rather resulted in individual particles being sedimented. This implies that sedimentation was not initiated at site \#3B until the more diffuse, later stages of the flow were passing this area, and at this stage, the flow may

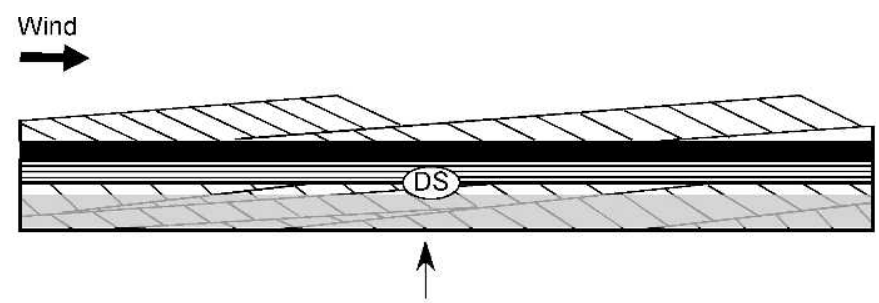

Process: Water table drops and/or sand supply increases Response: Dune development

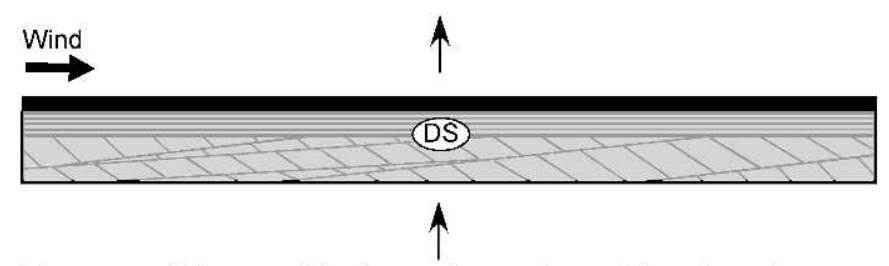

Process: Water table rises above depositional surface Response: Wet interdune/playa development

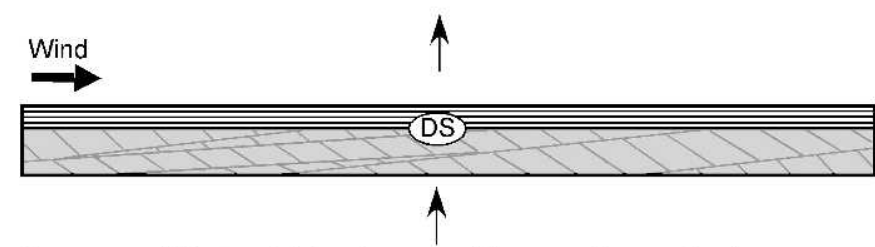

Process: Water table rises and/or sand supply decreases Response: Sand Sheet development

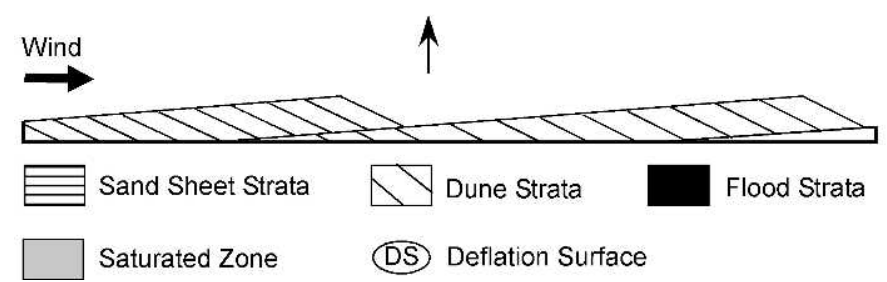

FIG. 8.-Depositional model for the Burns formation in the region of Eagle and Endurance craters (from Grotzinger et al. 2005) documenting a "wetting upward" eolian system. The lower unit accumulated by migration of eolian dunes. It is composed of sulfate-cemented altered basalt sand grains. Elevation of the water table (or decrease in sediment flux) resulted in the formation of a deflation surface (DS) down to the level of the capillary fringe of the water table. Sand sheet strata were deposited above the deflation surface. At some point, the groundwater table breached the surface, resulting in deposition of subaqueous interdune sandstones ("Flood Strata"). To date, only one such cycle has been confirmed by Opportunity, but such a model predicts the cycle would be repeated as the level of the groundwater table fluctuated.

have separated from the substrate so traction was not possible-as in the pyroclastic flow transforming into a buoyant plume in the Mount St. Helens eruption (Sparks et al. 1986).

Another type of massive impact deposit has been described by Branney and Brown (2011) from the Stac Fada impact layer in Scotland. This impact layer is up to $10 \mathrm{~m}$ thick and composed of reverse graded and then disorganized bedded, matrix-supported breccia without accretionary lapilli. This section fines upward (coarse tail grading) to massive, matrix-supported pebble breccia with accretionary 


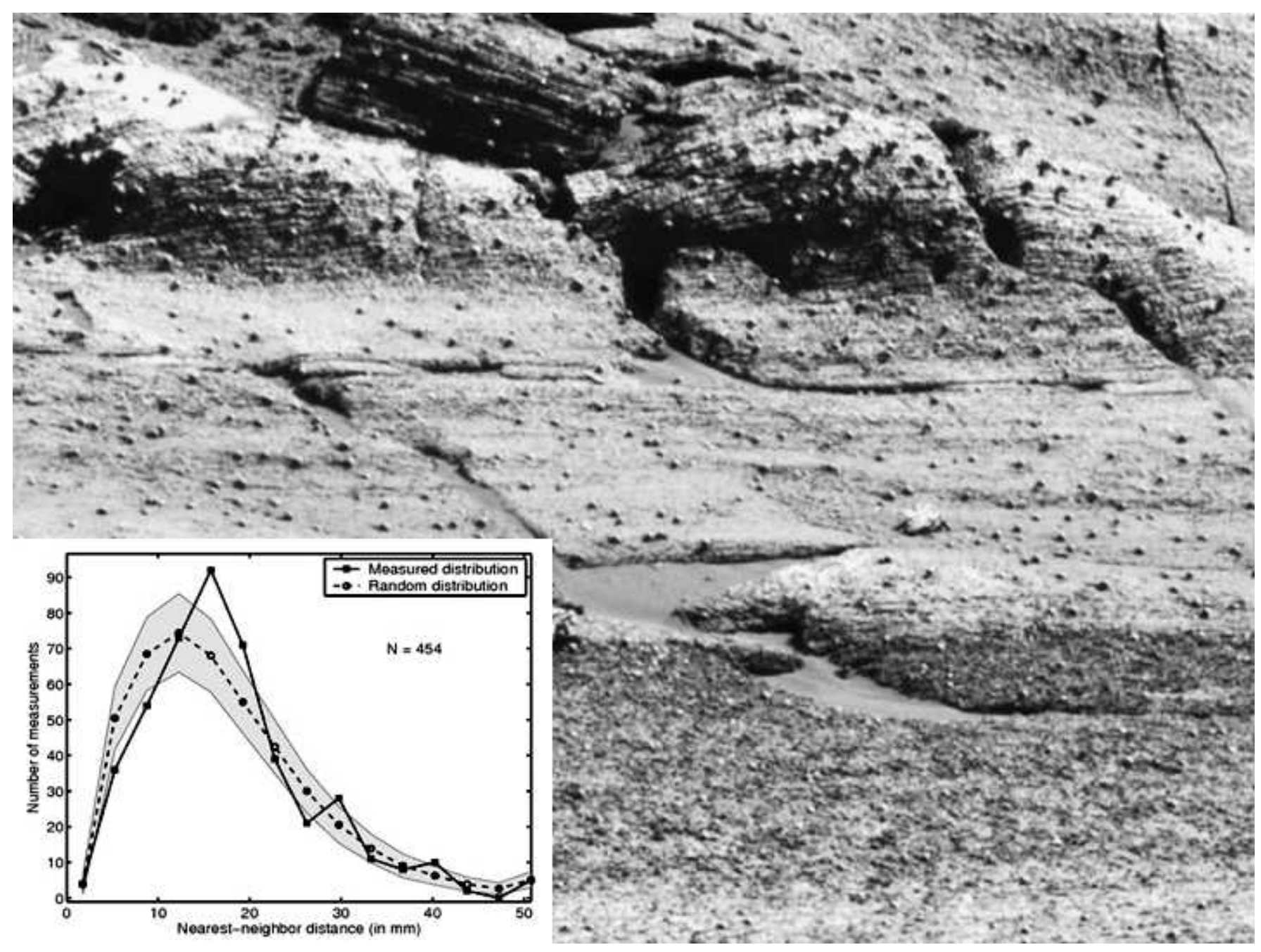

FIG. 9.- Image of upper part of Burns formation, Endurance crater, Meridiani Planum, Mars. Lower, dark-toned unit is overlain by upper, lighttoned unit, which represents a diagenetic alteration front (see Figure 5c of Grotzinger et al. [2005] for image location and camera parameters). Note that spherules are highly dispersed throughout both facies and are not concentrated along stratification boundaries. Inset shows plot of frequency versus nearest-neighbor-distance for spherules (solid line) from four locations compared to a numerical random distribution (dashed line). This distribution shows quantitatively what can be observed qualitatively in the underlying image: that the spherules are highly dispersed, which generally supports of a model of formation by precipitation at point sources by iron-bearing pore fluids. After McLennan et al. (2005).

lapilli. Faint bedding developed immediately below a capping, thin layer of clast-supported rainout ash pellets. Branney and Brown (2011) hypothesize that this deposit formed from a high-concentration, steady, granular fluid-based density current. This is a higher concentration flow than that described for the Sudbury impact, possibly denoting a closer position to its source. As no layering is developed in the majority of the deposit, the accretionary lapilli are scattered throughout the upper portion of the layer.

Aside from thin, massive impact deposits, probably formed by the waning suspension cloud, or representing tsunami reworking (Pufahl et al. 2007), the accretionary lapilli-bearing Sudbury impact deposits are internally organized assemblages. They have well-developed stratification, and accretionary lapilli were sorted by traction processes according to their size and mass. Velocity variations in the surge, caused by turbulent eddies, separated the different medium-grained sand to pebble size fractions in transport into distinct beds. Only where sedimentation from suspension formed a massive layer, or where a limited number of accretionary lapilli were eroded from a clastsupported lapilli bed and rolled into a sand-dominated area, were isolated lapilli observed in thicker sandy units. In the latter example, the lapilli are commonly found at or near the base of the sandstone bed as continued sand deposition buried the source of the lapilli.

\section{Relevance for the Burns Formation and Other Deposits on Mars}

Two alternatives to the depositional model outlined previously have been suggested for the Burns formation. McCollom and Hynek (2005) argued that the sequence was a volcanic base surge deposit that experienced in situ isochemical acid-sulfate alteration in an acid-foglike setting. They interpreted the spherules to represent diagenetic concretions formed during alteration. Knauth et al. (2005) suggested that the Meridiani strata were formed by an impact-induced base surge, 


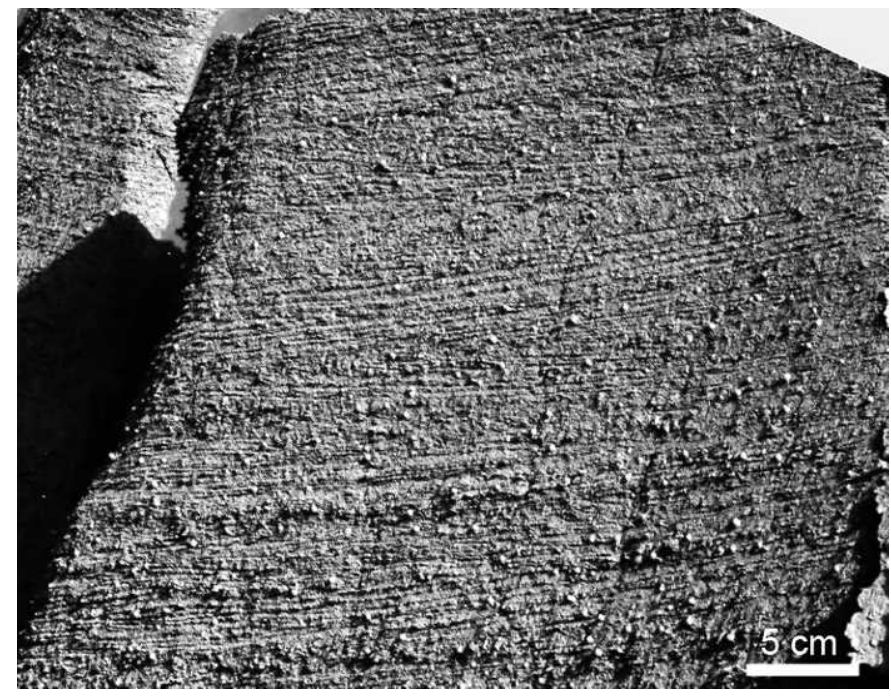

FIG. 10.-Well-stratified sandstone in Burns formation showing lowangle truncation surfaces and cross-stratification, typical of traction sedimentation processes in turbulent flows. Note dispersion of spherules throughout deposit and absence of concentration along bedding planes and scour surfaces. This outcrop ("Tipuna") represents the uppermost $30-40 \mathrm{~cm}$ of the Burns middle unit. The image was obtained on sol 307.

whereby an iron meteorite struck an area with buried sulfate-rich evaporite deposits. Knauth et al. (2005) contended that the Burns spherules are iron condensation spherules - not diagenetic concretions. These alternative models have not been widely accepted in part because they are inconsistent with the regional geological context, which provides no evidence for contemporaneous sources of volcanism or age-appropriate impacts of sufficient size (see McLennan and Grotzinger 2008). In addition, there are other, more specific factors that are inconsistent with these models. Here, we specifically consider the possibility that the Burns formation spherules formed as impactinduced accretionary lapilli, or from condensation. In either case they would have been free particles interacting with the current that transported other sediments from the site of impact to the site of deposition, and thus the Sudbury impact deposit constitutes an important analog.

If the spherules are accretionary lapilli or condensation droplets, as might be predicted to exist in an impact deposit, they should show concentrations along bedding planes, as is the case for the Sudbury impact deposit. In contrast, in all outcrops observed to date by Opportunity, spherules are always highly dispersed relative to bedding (McLennan et al. 2005). Figure 12 shows three separate scenarios for the potential origin of spherules in the Burns formation. In the first case (Fig. 12, left), outsized particles (spherules) are entrained within a hyperconcentrated flow that causes them to be dispersed. The shear strength of such a fluid is high enough that viscous forces dominate over gravitational forces, and the larger, heavier particles do not preferentially settle out to form discrete beds (Nemec and Steel 1984). Note that ash plumes rising from the surface where a surge cloud loses contact with the ground, as sometimes happens (from the initial ash plume or from retrogressive collapse of loose material) (Branney and Kokelaar 2003) can deposit ash and accretionary lapilli directly from suspension with no traction (this likely occurred at site \#3B). However, deposits produced directly from suspension result in massive bedding in which deposits are poorly sorted and lack well-defined stratification;

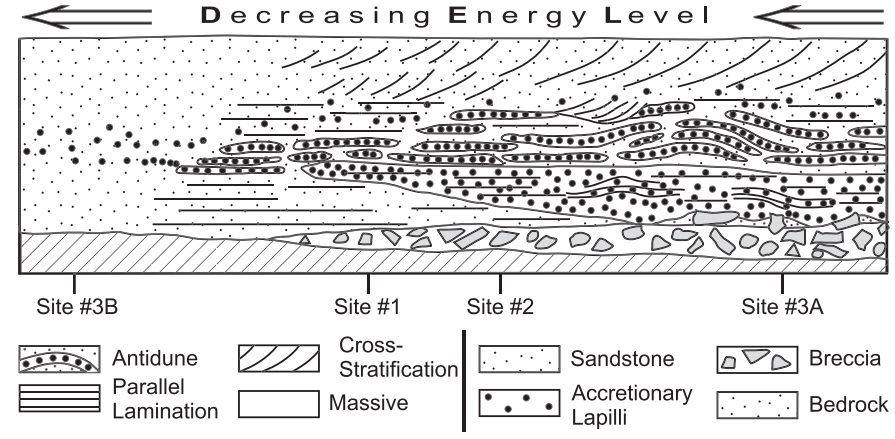

FIG. 11.-Depositional model for units associated with accretionary lapilli deposited by the Sudbury impact event. Decreasing energy of the flow does not necessarily reflect proximal to distal positioning as topography exerted a major control on the energy level that existed during deposition. The higher-energy deposits have a basal breccia zone with locally derived debris erosively overlain by upper-flow-regime, parallel-laminated and undulatory laminated (antidune) accretionary lapilli and sandstone. This fines upward, where the upper-flow-regime bed forms are replaced by lower-flowregime trough cross-stratification. At this point, accretionary lapilli become rare. With decreasing energy levels, the basal breccia zone does not form, and accretionary lapilli become less numerous and confined to thinner beds. Upper-flow-regime parallel-lamination and some antidunes formed from hydraulic jumps are still present. At the lowest energy levels studied, the flow was probably not in contact with the bed, and a thinner, massive deposit developed.

this contrasts with the Burns formation, in which millimeter-scale lamination is pervasively developed (Grotzinger et al., 2005, 2006; Metz et al. 2009; Edgar et al. this volume).

In the second scenario (Fig. 12, center), the outsized particles (e.g., lapilli, condensation spherules) are mixed with other sediments in a more dilute flow that is fully turbulent. This turbulence results in velocity fluctuations during deposition that will produce beds of coarser- and finer-grained sediment. Movement of sediment in traction under turbulent flow can also lead to the development of bed forms, the migration of which may create scour surfaces, and multiple flow events may cause stacking of beds separated by hiatal surfaces. In this type of flow, gravitational forces may dominate, so that general behavior according to Stokes law is predicted. Particles will sort themselves given their respective settling velocities $\left(w_{\mathrm{s}}\right)$

$$
w_{s}=\frac{2 g r^{2}\left(\rho_{p}-\rho_{f}\right)}{9 \mu}
$$

where $r$ is the radius of the particle, $\rho$ is the density of the particle or fluid, $\mu$ is the viscosity of the fluid, and $g$ is the gravitational constant. Hydraulic segregation of particles with different settling velocities is why sorting occurs, and why outsized particles (for example, lapilli) are commonly concentrated along bedding planes in successions of flow-emplaced strata (see Figs. 2-5; Lowe et al. 2003). This is a distinctive textural attribute of the well-stratified Sudbury deposits, as well as other well-stratified volcanic surge deposits. In contrast, the Burns formation lacks evidence for hydrodynamic sorting of spherules despite being well stratified and showing clear evidence for scouring by currents, and also reworking above erosional surfaces. Equation 1 shows that the settling velocity goes as the square of the grain radius, so the outsized spherules - if sediment particles - are predicted to drop out very rapidly. In the Burns formation, they are on the order of 5-10 
times larger than the grains that make up the stratified matrix in which the spherules are embedded (Grotzinger et al. 2005, McLennan et al. 2005), so they should show strong sorting, as in the Sudbury deposit. Furthermore, compositional data indicate that the density of the spherules is likely higher than the density of the grains in the stratified matrix; the former consist of a significant fraction of hematite, up to 50-60\% (McLennan et al. 2005). Again, Eq. 1 shows that the density difference between the particles and the fluid in which they are makes a difference, so the hematitic spherules are again expected to have preferentially higher settling velocities, which will result in further enhanced separation of the spherule and sand fractions during deposition (Saxton et al. 2008). Finally, it is worth noting that the smaller $g$ of Mars has no substantial effect on the relative settling velocities of the grains.

In the third scenario, spherules are dispersed across all strata and show no concentration, even at obvious erosional surfaces, such as the lower-middle unit boundary (Wellington contact) at Burns cliff (Grotzinger et al. 2005). Spherules are not concentrated along these or any other scour surfaces, despite clear evidence that the surfaces truncate spherule-bearing strata and represent erosion of spherulebearing matrix sediments. This strongly indicates that the spherules must have developed in situ, after deposition of the sediments, favoring an origin as depicted in this third scenario. This interpretation is supported by the occurrence of "doublets" and even "triplets," where spherules touch and overgrow each other (see Figure $7 \mathrm{~g}$ in McLennan et al. 2005).

In summary, the textural relationship between the outsized spherules in the Burns formation and the well-laminated sandstone matrix does not support their origin as sedimentary particles. This applies regardless of whether the spherules are interpreted to be accretionary lapilli or condensation droplets. In each case, these spherules should react in the flow as heavy particles that would preferentially travel in traction and be sedimented together at velocities that would segregate the majority of the sand to the saltation and suspension populations (Saxton et al. 2008). Concentrations of spherules should be particularly abundant along scour surfaces, where erosive lags would have developed. In addition, shielding from the current in scour troughs would have led to preferential deposition of material in traction transport, i.e., the much larger and denser spherules. Indeed, this is exactly what is observed in the spherule-bearing strata of the Sudbury impact deposits. These deposits highlight the improbability of the spherules in the strata observed at Meridiani Planum being related to an impact event. The Sudbury impact deposits also provide clues as to what a spherule deposit on Mars, which is related to an impact, may look like.

\section{CONCLUSION}

This study clearly outlines a means of distinguishing between impact-generated spherules and concretions. The differences produced by physical processes are of primary importance because the use of mineralogy or geochemistry can provide misleading results. The Sudbury impact accretionary lapilli present in the northern portion of their outcrop area have been massively replaced by ferroan dolomite. Thus, their mineralogy and geochemistry cause them to appear to be carbonate-rich concretions rather than lapilli generated by an impact on sialic crust. If impact-generated lapilli on Mars prove to be just as susceptible to replacement, their distribution within the strata will be of paramount importance in formulating the correct interpretation of their origin.

Differentiating between impact- and volcanic eruption-produced accretionary lapilli is difficult (Branney and Brown 2011). Here, the associated lithofacies become important. In an impact event, the initial burst of energy is directed down into the substrate, producing intense shock waves. In a volcanic eruption, the energy is released in an
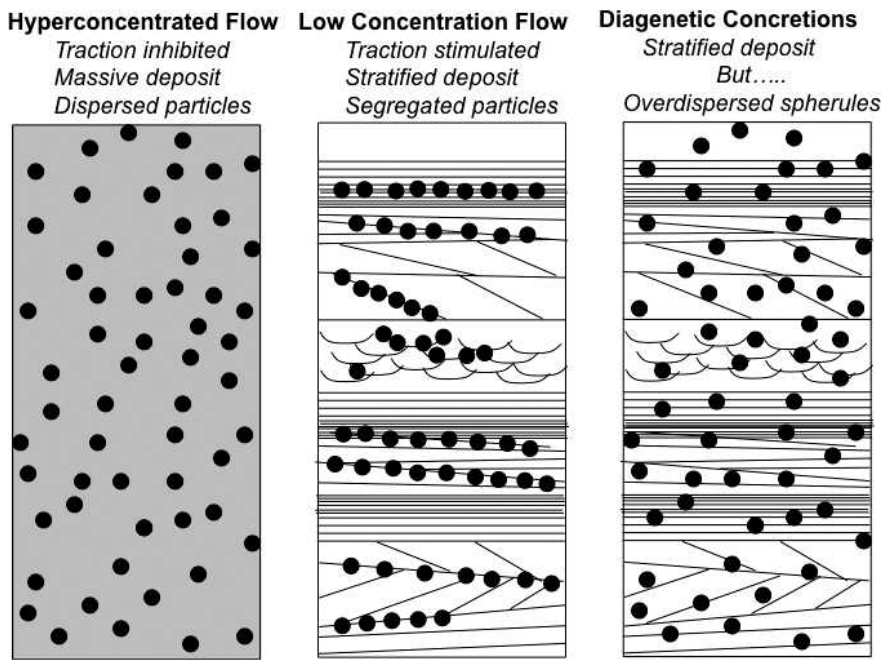

FIG. 12.-Models for relationships between spherule distribution and sedimentologic texture. Left) Spherules are dispersed within a massive matrix of poorly sorted, finer-grained sediments. This texture is commonly observed in debris flows, or even hyperconcentrated flows, where flows may be nonturbulent and suspended particle concentrations are very high (Jakob and Hungr 2005). Viscous fluid forces dominate the flow, and a combination of high fluid shear strength coupled with hindered settling of particles results in dispersion (poor sorting) of all grain sizes. The presence of excellent stratification excludes this option for the Burns formation, even though the spherules are highly dispersed. Center) Flows with low sediment concentrations are fully turbulent, and particles will become hydraulically sorted according to grain size. Heavier particles, such as spherules, will be systematically concentrated as erosive lags along scour surfaces, where smaller (less massive) particles are removed by turbulent eddies in the scour pits of bed forms. The Burns formation does not show evidence for concentration of the spherules as this scenario would predict. Right) spherules here are highly dispersed relative to primary bedding features, including scour-related truncation surfaces and other stratigraphic disconformities. The absence of concentrated spherule beds points to a different origin, perhaps as diagenetic concretions. In this case, the mineralizing pore fluids move through the previously deposited sediments, and precipitation occurs at discrete points. Concretions then form by growing radially in an outward direction from the point.

upward direction, with only minor resultant earthquake activity. Ground movement distal to the Sudbury impact event shattered the bedrock (Addison et al. 2010). This debris was entrained by the leading edge of the base surge and swept into topographic lows. Thus, at many outcrop occurrences of the Sudbury impact layer, the basal deposits are matrix-supported, cobble to boulder breccias composed of local material. They commonly do not have impact-derived sediment, i.e., devitrified glass or accretionary lapilli, mixed with the local debris. This type of basal unit, in conjunction with a generally broken and faulted underlying basement, is uniquely characteristic of impactproduced deposits. In addition, if the target rock included sedimentary strata, some far-traveled pieces of nonvolcanic debris may be present higher in the deposit. In contrast, large volcanic eruptions on Mars would be expected to have been relatively nonexplosive, due to the 
composition of the magma, and if a violent eruption did occur, it would have only rarely entrained nonvolcanic fragments.

The formation of ash pellets and accretionary lapilli requires moisture in the impact debris cloud. Some moisture can be released by the devolatilization of the target rocks. However, more favorable conditions for ash aggregates are produced by a wet sedimentary substrate, surface water, or atmospheric moisture incorporated into the debris cloud (Branney and Brown 2011). Thus, the presence or absence of ash pellets and accretionary lapilli in deposits of impact debris may provide information on surface moisture in the region at the time of impact.

\section{ACKNOWLEDGMENTS}

We would like to thank John Spray and Horton Newsom for critical reviews, in addition to comments by Editor Ralph Milliken, which led to improvements in the manuscript. Drafting of figures related to the Sudbury deposits was performed by Sam Spivik. Funding for this work was provided by Lakehead University and a Discovery Grant from the National Science and Engineering Research Council of Canada to P.W.F. The NASA Astrobiology Institute provided funding for J.P.G. and L.A.

\section{REFERENCES}

Addison WD, Brumpton GR, Davis DW, Fralick PW, Kissin SA. 2010. Debrisites from the Sudbury impact event in Ontario, north of Lake Superior, and a new age constraint: are they base-surge or tsunami deposits. In Gibson RL, Reimold WU (Editors). Large Meteorite Impacts and Planetary Evolution IV. Geological Society of America, Boulder, CO. Special Paper 465 , p. 245-268.

Addison WD, Brumpton GR, Vallini DA, McNaughton NJ, Davis DW, Kissin SA, Fralick PW, Hammond AL. 2005. Discovery of distal ejecta from the 1850 Ma Sudbury impact event. Geology 33:193-196.

Arnott RWC, Hand BM. 1989. Bedforms, primary structures and grain fabrics in the presence of suspended sediment rain. Journal of Sedimentary Petrology 59:1062-1069.

Barlow NG. 2005. A review of Martian impact crater ejecta structures and their implications for target properties. In Kenkmann T, Horz F, Deutsch A, (Editors). Large Meteorite Impacts III. Geological Society of America, Boulder, CO. Special Paper 384, p. 433-442.

Branney MJ, Brown RJ. 2011. Impactoclastic density current emplacement of terrestrial meteorite-impact ejecta and the formation of dust pellets and accretionary lapilli: evidence from Stac Fada, Scotland. The Journal of Geology 119:275-292.

Branney MJ, Kokelaar P. 2003. Introduction and key concepts. In Branney MJ, Kokelaar P (Editors). Pyroclastic Density Currents and the Sedimentation of Ignimbrites. Geological Society of London. Memoir 27, p. 1-5.

Brown RJ, Branney MJ, Maher C, Davila-Harris P. 2010. Origin of accretionary lapilli within ground-hugging density currents: evidence from pyroclastic couplets on Tenerife. Geological Society of America Bulletin 122:305-320.

Burt DM, Knauth LP, Wohletz KH, Sheridan MF. 2008. Surge deposits misidentification at Spor Mountain, Utah and elsewhere: a cautionary message for Mars. Journal of Volcanology and Geothermal Research 177:755-759.

Cannon WF, Schulz KJ, Horton JW, Kring DA. 2010. The Sudbury impact layer in the Paleoproterozoic iron ranges of northern Michigan, USA. Geological Society of America Bulletin 122:50-75.

Carey SN. 1991. Transport and deposition of tephra by pyroclastic flows and surges. In Fisher RV and Smith GA (Editors). Sedimentation in Volcanic Settings. Society of Economic Paleontologists and Mineralogists, Tulsa, OK. Special Publication 45, p. 39-57.

Chough SK, Sohn YK. 1990. Depositional mechanics and sequences of base surges, Songaksan tuff ring, Cheju Island, Korea. Sedimentology 37:11151135 .

Clark BC, 23 others. 2005. Chemistry and mineralogy of outcrops at Meridiani Planum. Earth and Planetary Science Letters 240:73-94.

Crowe BM, Fisher RV. 1973. Sedimentary structures in base-surge deposits with special reference to cross-bedding, Ubehebe Craters, Death Valley, California. Geological Society of America Bulletin 84:663-682.

Druitt TH. 1992. Emplacement of the 18 May 1980 lateral blast deposit ENE of Mount St Helens, Washington. Bulletin of Volcanology 54:554-572.

Earth Impact Database. 2004. Earth Impact Database. www.unb.ca/passe/ ImpactDatabase. Accessed October 12, 2004.

Fralick PW, Burton J. 2008. Geochemistry of the Paleoproterozoic Gunflint Formation carbonate: implications for early hydrosphere-atmosphere evolution. Geochimica et Cosmochimica Acta 72:A280.

Fan C, Xie H, Schulze-Makuch D, Ackley S. 2010. A formation mechanism for hematite-rich spherules on Mars: Planetary and Space Science 58:401-410.

Gencalioglu-Kuscu G, Atilla C, Cas RAF, Kuscu L. 2007. Base surge deposits, eruption history, and depositional processes of a wet phreatomagmatic volcano in Central Anatolia (Cora Maar). Journal of Volcanology and Geothermal Research 159:198-209.

Golden DC, Ming DW, Morris RV, Graff TG. 2008. Hydrothermal synthesis of hematite and jarosite: implications for diagenesis and hematite spherule formation in sulfate outcrops at Meridiani Planum, Mars. American Mineralogist 93:1201-1214.

Grant JA, Rossman PI, Grotzinger JP, Milliken RE, Tornabene LL, McEwen AS, Weitz CM, Squyres SW, Glotch TD, Thomson BJ. 2008. HiRISE imaging of impact megabreccia and sub-meter aqueous strata in Holden Crater, Mars. Geology 36:195-198.

Graup G. 1981. Terrestrial chondrules, glass spherules and accretionary lapilli from the suevite, Ries Crater, Germany. Earth and Planetary Science Letters 55:407-418.

Grotzinger JP, Arvidson RE, Bell JF, Calvin WM, Clark BC, Fike DA, Golombek MP, Greeley R, Haldemann A, Herkenhoff KE, Jollif BL, Knoll AH, Malin MC, McLennan SM, Parker T, Soderblom L, Sohl-Dickstein JN, Squyres SW, Tosca NJ, Watters WA. 2005. Stratigraphy and sedimentology of a dry to wet eolian depositional system, Burns Formation, Meridiani, Mars. Earth and Planetary Science Letters 240:11-72.

Grotzinger JP, Bell J, Herkenhoff K, Johnson J, Knoll A, McCartney E, McLennan S, Metz J, Moore J, Squyres S, Sullivan S, Aharonson O, Jollif B, Golombek M, Lewis K, Parker T, and Soderblom J. 2006. Sedimentary textures formed by aqueous process, Erebus crater, Meridiani Planum, Mars. Geology 34:1085-1088.

Jakob M, Hungr O. 2005. Debris-Flow Hazards and Related Phenomena. Springer, Berlin. $781 \mathrm{p}$.

Jirsa MA. 2008. Scientists unearth ancient impact's secrets. Astronomy 36(12):32-37.

Kenkmann T, Schonian F. 2006. Ries and Chicxulub: impact craters on Earth provide insights for Martian ejecta blankets. Meteoritics and Planetary Science 41:1587-1603.

Knauth LP, Burt DM, Wohletz KH. 2005. Impact origin of sediments at the Opportunity landing site on Mars. Nature 438:1123-1128.

Koeberl C, Brandstatter F, Glass BP, Hecht L, Mader D, Reimold WU. 2007. Uppermost impact fallback layer in the Bosumtwi crater (Ghana): mineralogy, geochemistry, and comparison with Ivory Coast tektites. Meteoritics and Planetary Science 42:709-729.

Krogh TE, Davis DW, Corfu F. 1984. Precise U-b and zircon and baddeleyite ages for the Sudbury area. In Pye EG, et al. (Editors). The Geology and Ore Deposits of the Sudbury Structure. Ontario Geological Survey, Toronto, Canada. Special Volume 1, p. 431-446.

Leeder MR. 1982. Sedimentology, Process and Product. Unwin-Hyman, London. $344 \mathrm{p}$.

Lowe DR, Byerly GR, Kyte FT, Shukolyukov A, Krull A, Asaro F. 2003. Characteristics, origin and interpretation of Archean impact produced spherule beds, 3.47-3.22 Ga, in the Barberton Greenstone Belt, South Africa: keys to the role of large impacts on the evolution of early Earth. Astrobiology 3:7-48.

Malin MC, Edgett KS. 2000. Sedimentary rocks of early Mars. Science 290:1927-1937.

Malin MC, Edgett KS. 2001. Mars Global Surveyor Mars Orbiter Camera: interplanetary cruise through primary mission. Journal of Geophysical Research 106:23429-23570, DOI 10.1029/2000JE001455

Masaitis V. 2003. Obscure-bedded ejecta facies from the Popigai impact structure, Siberia; lithological features and mode of origin. In Koeberl C, 
Martinez-Ruiz FC (Editors). Impact Markers in the Stratigraphic Record. Springer, Berlin, Impact Studies 26, p. 137-162.

McCollom TM, Hynek BM. 2005. A volcanic environment for bedrock diagenesis at Meridiani Planum on Mars. Nature 438:1129-1131.

McLennan SM, Grotzinger JP. 2008. The sedimentary rock cycle of Mars. In Bell JF (Editor). The Martian Surface; Composition, Mineralogy and Physical Properties. Cambridge University Press, New York. p. 541-577.

McLennan SM, 30 others. 2005. Provenance and diagenesis of the Burns Formation. Meridiani Planum, Mars. Earth and Planetary Science Letters 240:95-121.

Melosh HG. 1989. Impact Cratering: A Geologic Process. Oxford University Press, New York. 245 p.

Metz JM, Grotzinger JP, Rubin DM, Lewis KW, Squyres SW, Bell JF. 2009. Sulfate-rich eolian and wet interdune deposits, Erebus Crater, Meridian Planum, Mars. Journal of Sedimentary Research 79:247-264.

Mouginis-Mark PJ, Garbeil H. 2007. Crater geometry and ejecta thickness of the Martian impact crater Tooting. Meteoritics and Planetary Science 42:16151625 .

Nemec W, Steel RJ. 1984. Alluvial and coastal conglomerates: their significant features and some comments on gravelly mass-flow deposits. In Koster EH, Steel RH (Editors). Sedimentology of Gravels and Conglomerates. Canadian Society of Petroleum Geology, Calgary, Canada. Memoir 10, p. 1-31.

Newsom HE, Grauo G, Iseri D, Geissman JW, Keil K. 1990. The formation of the Reis Crater, West Germany: evidence of atmospheric interactions during a large cratering event. In Sharpton VL, Ward PD (Editors), Global Catastrophies in Earth History: An Interdisciplinary Conference on Impacts, Volcanism and Mass Mortality. Geological Society of America, Boulder, CO. Special Paper 247, p. 195-206.

Orton GJ. 1996. Volcanic environments. In Reading HG (Editor). Sedimentary Environments: Processes, Facies and Stratigraphy. Blackwell Science, London. p. 485-567.

Osinski G. 2006. Effects of volatiles and target lithology on the generation and emplacement of impact crater fill and ejecta deposits on Mars. Meteoritics and Planetary Science 41:1571-1586.

Pope KO, Ocampo AC, Fischer AG, Alvarez W, Fouke BW, Webster CL, Vega FJ, Smit J, Fritsche AE, Claeys Ph. 1999. Chicxulub impact ejecta from Albion Island, Belize. Earth and Planetary Science Letters 170:351-364.

Pope KO, Ocampo AC, Fischer AG, Vega FJ, Ames DE, King DT, Fouke BW, Wachtman RJ, Kletetschka G. 2005. Chicxulub impact ejecta deposits in southern Quintana Roo, Mexico, and central Belize. In Kenkmann T, Horz F, Deutsch A (Editors). Large Meteorite Impacts III. Geological Society of America, Boulder, CO. Special Paper 384, p. 171-190.

Pufahl PK, Hiatt EE, Stanley CR, Morrow JR, Nelson GJ, Edwards CT. 2007. Physical and chemical evidence for the 1850 Ma Sudbury impact event in the Baraga Group, Michigan. Geology 35:827-830.

Saxton J, Fralick PW, Panu U, Wallace K. 2008. Density segregation of minerals during high-velocity transport over a rough bed: implications for the formation of placers. Economic Geology 103:1657-1664.

Schmincke H.-U, Fisher RV, Waters AC. 1973. Antidune and chute and pool structures in base surge deposits of the Laacher see area, Germany Sedimentology 20:553-574.

Smith GA, Katzman D. 1991. Discrimination of eolian and pyroclastic-surge processes in the generation of cross-bedded tuffs, Jemez Mountains volcanic field, New Mexico. Geology 19:465-468.

Sparks RSJ, Moore JC, Rice CJ. 1986. The initial giant umbrella cloud of the May 18, 1980, explosive eruption of Mount St Helens. Journal of Volcanological and Geothermal Research 28:257-274.

Spray JG, Butler HR, Thompson LM. 2004. Tectonic influences on the morphometry of the Sudbury impact structure: implications for terrestria cratering and modeling. Meteoritics and Planetary Science 39:287-301.

Squyres SW, Aharonson O, Arvidson RE, Bell JF, Cristensen PR, Clark BC, Crisp JA, Farrand W, Glotch T, Golombek MP, Grant J, Grotzinger J, Herkenhoff KE, Johnson JR, Jollif BL, Knoll AH, McLennan SM, McSween HY, Moore JM, Rice JW, Tosca N. 2006a. Planetary science: bedrock formation at Meridiani Planum. Nature 443. DOI 10.1038/nature05212

Squyres SW, Arvidson RE, Bell JF, et al. 2004a. The Opportunity rover's Athena science investigation at Meridiani Planum, Mars. Science 306:1698-1703.

Squyres SW, Grotzinger JP, Arvidson RE, Bell JF, Calvin W, Christensen PR,
Clark BC, Crisp JA, Farrand WH, Herkenhoff KE, Johnson JR, Klingelhofer G, Knoll AH, McLennan SM, McSween HY, Morris RV, Rice JW, Rieder R, Soderblom LA. 2004b. In situ evidence for an ancient aqueous environment at Meridiani Planum, Mars. Science 306:1709-1714.

Squyres SW, Knoll AH. 2005. Sedimentary rocks at Meridiani Planum: origin, diagenesis and implications for life on Mars. Earth and Planetary Science Letters 240:1-10.

Squyres SW, Knoll AH, Arvidson RE, Clark BC, Grotzinger JP, Jollif BL, McLennan SM, Tosca N, Bell JF, Calvin W, Farrand WH, Glotch TD, Golombek MP, Herkenhoff KE, Johnson JR, Klingelhofer G, McSween HY, Yen AS. 2006b. Two years at Meridiani Planum: results from the Opportunity rover. Science 313:1403-1407.

Warme JE, Morgan M, Kuehner H.-C. 2002. Impact generated carbonate accretionary lapilli in the Late Devonian Alamo Breccia. In Koeberl C, MacLeod KG (Editors). Catastrophic Events and Mass Extinctions; Impacts and Beyond. Geological Society of America, Boulder, CO. Special Paper 356, p. $489-504$.

Wilson CJN, Walker GPL. 1982. Ignimbrite depositional facies: the anatomy of a pyroclastic flow. Journal of the Geological Society of London 139:581-592.

Wohletz KH, McGetchin TR, Sandford MT, Jones EM. 1984. Hydrodynamic aspects of caldera-forming eruptions: numerical models. Journal of Geophysical Research 89:8265-8269. 